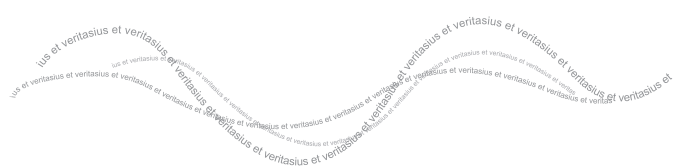

\title{
Perspectivas del derecho fiscal comparado: Criptomonedas, transacciones y eventos impositivos. Tratamiento tributario en el Perú, problemas y recomendaciones $\left.{ }^{*}\right)$
}

\author{
A view from comparative tax law: Cryptocurrencies, transactions and taxable \\ events. Tax treatment in Peru, problems and recommendations
}

\author{
Luis Durán Rojo ${ }^{(*)}$ \\ Pontificia Universidad Católica del Perú (Lima, Perú) \\ Ernesto Pachas Luna $\left.{ }^{(* \star}\right)$ \\ Pontificia Universidad Católica del Perú (Lima, Perú)
}

\begin{abstract}
Resumen: Actualmente, nos encontramos ante un aumento significativo de transacciones con criptomonedas como alternativa al sistema tradicional de pago, e incluso como medio de inversión; por lo que la mayoría de los países en el mundo ya han tomado acción sobre el tratamiento tributario aplicable a dichas operaciones: Existen diversos pronunciamientos emitidos por las autoridades tributarias del mundo $y$, en algunas jurisdicciones, ya se han adoptado medidas legislativas específicas para regular los efectos tributarios de las transacciones con criptomonedas, principalmente en materia de impuestos sobre la renta e impuestos al valor agregado. Por ello, resulta necesario evaluar el tratamiento tributario actual sobre las actividades realizadas con criptomonedas en la legislación peruana, para efectos de identificar -desde una perspectiva comparada- los principales problemas de carácter impositivo y, a su vez, brindar algunos lineamientos a tener en cuenta para una eventual y necesaria regulación.
\end{abstract}

Palabras clave: Derecho Tributario - Criptomonedas - Legislación Comparada Impuesto a la Renta - Impuesto al Valor Agregado - Intercambios con criptomonedas - Minería de criptomonedas - Principios Constitucionales

\begin{abstract}
Currently, we are facing a significant increase in transactions with cryptocurrencies as an alternative to the traditional payment system, and even as an investment; so, most countries in the world have already taken action on the tax treatment of these transactions: There are various pronouncements issued by the tax authorities in the world and, in some jurisdictions, specific legislative measures have been adopted to regulate the tax effects of transactions with cryptocurrencies. For that reason, it is necessary to evaluate the current tax treatment of activities with cryptocurrencies in Peruvian legislation, in order to identify -from a comparative perspective- the main tax problems and to provide some guidelines to be taken into account for an eventual regulation.
\end{abstract}

$\left(^{*}\right) \quad$ Nota del Equipo Editorial: Este artículo fue recibido el 16 de setiembre de 2021 y su publicación fue aprobada el 17 de noviembre de 2021.

${ }^{(* *}$ Abogado. Magíster en Derecho por la Pontificia Universidad Católica del Perú. Profesor del Departamento de Derecho de la PUCP, Lima, Perú. Director de la revista Análisis Tributario. ORCID: https://orcid.org/0000-0001-6200-6887. Correo electrónico: Iduran@pucp.edu.pe.

${ }^{* * *}$ Bachiller en Derecho por la Pontificia Universidad Católica del Perú, Lima, Perú. Miembro extraordinario de IUS ET VERITAS y miembro del Consejo Directivo durante el semestre 2016-2. Miembro de la firma EY Perú - Litigation Tax Services. ORCID: https:// orcid.org/0000-0003-2474-6803. Correo electrónico: r.pachas@pucp.pe. 
Perspectivas del derecho fiscal comparado: Criptomonedas, transacciones y eventos impositivos. Tratamiento tributario en el Perú, problemas y recomendaciones

A view from comparative tax law: Cryptocurrencies, transactions and taxable events. Tax treatment in Peru, problems and recommendations

Keywords: Tax Law - Cryptocurrencies - Comparative Legislation - Income Tax - Value Added Tax - Cryptocurrency Exchanges Cryptocurrency Mining - Constitutional Principles

\section{Introducción}

Debido a los acontecimientos generados por la pandemia sanitaria producto del Covid-19 y los recientes cambios políticos, económicos y sociales a nivel mundial, los agentes económicos se han visto en la necesidad de adoptar diversas medidas para salvaguardar su patrimonio y las inversiones. Ello ha dado paso a que se considere implementar el desarrollo de las nuevas tecnologías, entre las que se encuentra la inversión, adquisición y utilización de criptomonedas.

Esta realidad no es ajena al Perú, pues actualmente el uso de criptomonedas ha logrado un notable desarrollo: trabajos de "minado" para la creación de criptomonedas, funcionamiento de casas de cambio en las que se pueden adquirir criptomonedas, establecimientos que proveen bienes y servicios que aceptan como medio de pago a las criptomonedas, entre otros ${ }^{(1)}$.

No obstante, dada las características particulares de las criptomonedas -que principalmente recaen en el alto grado de anonimato, su impredecible volatilidad y la falta de respaldo económico-, se ha puesto en evidencia que el ordenamiento jurídico peruano resulta insuficiente para resolver una problemática latente: fuga de capitales, lavado de dinero, tráfico ilícito de bienes, evasión de impuestos, entre otros.

Atendiendo a esta problemática resulta necesario analizar el tratamiento tributario de las actividades realizadas con criptomonedas en el Perú para identificar los espacios de mejora que deberían darse en un corto plazo, pues nos encontramos ante una corriente de medidas legislativas adoptadas por diversas legislaciones en el mundo que nos sugieren dar un paso más en ese sentido.

Por ello, el presente artículo planteará las principales dificultades que afronta la tributación de las operaciones con criptomonedas en la legislación comparada y las soluciones brindadas, siguiendo las opiniones vertidas por las administraciones tributarias, las medidas legislativas adoptadas y las opiniones de diversos autores; con el objeto de atender el tratamiento tributario actual de dichas operaciones en el ordenamiento jurídico peruano desde una perspectiva internacional, y sugerir algunas medidas que podrían resultar aplicables.

\section{Criptomonedas: Consideraciones generales}

\begin{abstract}
2.1. Características de las criptomonedas Para efectos del presente artículo, al referirnos al término "criptomoneda" hacemos referencia genérica a todas las denominadas monedas virtuales o digitales que comparten características similares basadas en la criptografía y la tecnología "blockchain", pues en la actualidad existen diversos tipos de criptomonedas con ciertas particularidades, siendo las más conocidas el Bitcoin o el Ether, los Ilamados "stablecoins" como Libra, la criptomoneda de Facebook, o el Petro, criptomoneda de Venezuela.
\end{abstract}

El término criptomoneda hace clara alusión a la criptografía, "rama de las Matemáticas que hace uso de métodos y técnicas con el objeto principal de cifrar y/o proteger un mensaje o archivo por medio de un algoritmo, usando una o más claves, sin ellas será realmente difícil obtener el archivo original" (Varela, 2006, p. 3), que brinda -en el ámbito de las criptomonedas- un sistema de control y seguridad en los usuarios, que permite simplificar diversas transacciones.

Las criptomonedas son desarrolladas por la tecnología "blockchain", que otorga a los usuarios de estos diversos beneficios de carácter confidencial, económico, de seguridad, entre otros, pues se garantiza la seguridad y la veracidad de las transacciones. En efecto, el término "blockchain" -o cadena de bloques-, hace referencia a una estructura registro de información distribuido consistente en un conjunto de transacciones organizados y almacenados en bloques, que se encuentran ordenados cronológicamente y tienen un

(1) Actualmente, es posible invertir en mercados financieros para la adquisición de criptomonedas, ya que recientemente se han constituido Fondos de Inversión Cotizados o "Exchange-Traded Fund" que listan en bolsas de valores del extranjero, y a las cuales se puede acceder mediante la Bolsa de Valores de Lima. 
número de bloque -código alfanumérico conocido como "hash", y que funciona como una huella digital del bloque- y están firmados digitalmente por la persona que propone o valida dicho bloque (Allende, 2018, p. 5).

Así, tenemos que las criptomonedas utilizan la tecnología "blockchain" para proveer un método de pago electrónico que no necesita supervisión y elude el control de las instituciones financieras, siendo importante mencionar, que el éxito de las criptomonedas radica en la combinación de dicha tecnología y la implementación de protocolos de consenso que permiten obtener de manera eficiente la validación de las transacciones y recompensar a los validadores con una cierta cantidad de la moneda virtual, tal como sucedió en el caso de Bitcoin (Allende, 2018, p. 4).

Según el vocabulario propuesto por el Grupo de Acción Financiera Internacional (GAFI), las monedas virtuales son representaciones digitales de valor que pueden ser comercializadas de manera digital y funcionan como un medio de intercambio, una unidad de cuenta o un depósito de valor. No obstante, no tienen estatus de moneda de curso legal, siendo distintas a la moneda fíat o "moneda real" y al dinero electrónico, representación digital de moneda fíat (2015, p. 28). Ello debido principalmente a la falta de una entidad reguladora y el respaldo económico que permita garantizar su valor.

De una primera aproximación, podemos notar que la implementación de esta tecnología para optar por el uso de las criptomonedas en diversas transacciones podría generar ciertas ventajas competitivas, tales como la digitalización de las transacciones, la reducción del riesgo operativo, el ahorro en costos, entre otros ${ }^{(2)}$.

Sin embargo, debe advertirse que sus principales características son la transparencia -acceso de los usuarios al estado de los activos y el historial de transacciones-, la descentralización y la no necesidad de intermediarios, pues evita la intervención o verificación de las transacciones por parte de instituciones financieras (Allende, 2018, pp. 27-28), lo que convierte a las criptomonedas en un tipo de bienes con características muy particulares, pues si bien en un primer momento fueron creadas como una respuesta alternativa al sistema financiero tradicional -dado que en esencia funcionan como un método de pago o de intercambio para transacciones económicas- carecen de supervisión, control o respaldo de un sistema monetario.

Respecto a la descentralización de las criptomonedas, en palabras de Pérez-Carasa refiriéndose al caso de Bitcoin, ello supone que la criptomoneda no se encuentre controlada por ningún Estado, entidad financiera o compañía, lo que implicaría lo siguiente:

a) Ausencia de control y supervisión institucional en la emisión de bitcoins: La generación de bitcoins se gestiona por parte de la propia red de forma descentralizada, a través de una rutina matemática prefijada y de un proceso conocido como minería. De esta forma, no hay ninguna institución central capaz de supervisar o controlar la inflación de este tipo de criptodivisas.

b) Falta de regulación, supervisión y riesgos asociados: En este sentido, tanto el BCE, como la Reserva Federal Americana, han advertido sobre los peligros derivados de la falta de regulación de estas monedas, de los riesgos del soporte virtual y de la posible utilización de las mismas como medios de pago en actividades ilícitas. Del mismo modo, los organismos reguladores españoles, como el Banco de España o la Comisión Nacional del Mercado de Valores, han advertido de que, hasta la fecha, ninguna emisión de criptomoneda ha sido registrada, autorizada o verificada por ningún organismo supervisor en España, lo cual conlleva que no se apliquen a este tipo de inversiones ninguna de las garantías o protecciones previstas en la normativa relativa a productos bancarios o de inversión (2018, p. 136).

Asimismo, el autor -siguiendo a Pacheco Jiménez (2016)- agrega que pueden advertirse otras características adicionales inherentes a las criptomonedas, tales como intangibilidad, globalidad, inalterabilidad, confidencialidad, irreversibilidad de las transacciones, intercambiabilidad, entre otros (citado por Pérez-Carasa, 2018, p. 136).

Teniendo en cuenta ello, es claro que, debido a las particularidades de las criptomonedas, el valor de estas se encuentre sujeto únicamente a las reglas económicas del mercado, esto es, atendiendo a la oferta y la demanda. Es por esta razón que las criptomonedas son bienes altamente volátiles, cuya cotización resulta difícil de calcular.

(2) Véase Olea, N. (2019). Cinco beneficios de blockchain en las empresas ¿Por qué implementar Blockchain en su organización?. KMPG. https://home.kpmg/mx/es/home/tendencias/2019/08/cinco-beneficios-de-blockchain-en-las-empresas.html 
Perspectivas del derecho fiscal comparado: Criptomonedas, transacciones y eventos impositivos. Tratamiento tributario en el Perú, problemas y recomendaciones

A view from comparative tax law: Cryptocurrencies, transactions and taxable events. Tax treatment in Peru, problems and recommendations

\subsection{Adquisición, usos e inversión en criptomonedas:} Actividades principales $y$ agentes intervinientes

Para efectos del presente artículo, resulta importante destacar dos actividades básicas en relación a las criptomonedas: la minería como medio para la obtención de criptomonedas y el intercambio de criptomonedas, por dinero, otra criptomoneda o cualquier otro bien o servicio ${ }^{(3)}$. Asimismo, como punto adicional, comentaremos brevemente otros mecanismos de inversión utilizados actualmente para la adquisición de criptomonedas. Dicho esto, en las siguientes líneas, detallaremos algunos alcances generales de dichas operaciones, haciendo referencia a los agentes u operadores que intervienen en cada una de ellas.

\subsubsection{La minería como medio para la obtención de} criptomonedas y los mineros como agentes intervinientes La minería es un proceso matemático de validación de transacciones distribuidas que genera el "blockchain" para la creación de nuevas criptomonedas. Siguiendo a Allende, la minería o "minning" consiste en aquella actividad que emplea capacidad computacional para encontrar el código "hash" que permita la validación de bloques, terminología propia de la tecnología "blockchain" antes detallada, y, con ello, obtener las referidas criptomonedas. Así, se recompensa a aquellos usuarios que logren obtener el "hash" de los bloques, pues solo obtiene recompensa quien logra dicho objetivo (2018, p. 14).

Agrega el autor que en los blockchains criptomonetarios más importantes los mineros están organizados en "minning pools" que son grupos de personas uniendo recursos computacionales bajo la supervisión de un gestor que divide en partes proporcionales las recompensas en caso del minado(4) (Allende, 2018, p. 48).

Esta actividad requiere una fuerte inversión en equipos -capacidad de procesamiento- y sobre todo electricidad para soportar el trabajo de las computadoras de los mineros, pues la validación de transacciones no puede ser realizada manualmente por un ser humano (López, 2019, p. 142).

Dicho esto, podemos identificar principalmente a los intervinientes directos de esta actividad, conocidos como mineros, que son aquellas personas encargadas de la realización de procesos informáticos necesarios para el control y validación de las transacciones, y a quienes se les recompensa al lograr ese objetivo (González, 2018, p. 36).
Al respecto, cabe señalar que esta actividad podría ser llevada a cabo por una persona natural y por iniciativa propia de esta, como también por un grupo organizado que provea de las herramientas necesarias para obtener beneficios de manera eficiente, claro está que ello conlleva un interés netamente empresarial. En efecto, existen personas jurídicas que podrían contratan el personal necesario para realizar la actividad de minería en nombre suyo para obtener los beneficios de esta, obteniendo una contraprestación por ello, ya sea en criptomonedas o en dinero tradicional, dependiendo exclusivamente del acuerdo entre las partes en el ámbito privado.

\subsubsection{Intercambio de criptomonedas y los diversos agentes intervinientes (casas de cambio, poseedores y receptores de criptomonedas)}

En general, el intercambio de la criptomoneda o "trading" se basa en el uso de la criptomoneda como cualquier otro bien y -a su vez- como un medio de pago, pues siempre podrá intercambiarse por otro bien, incluyendo a la propia criptomoneda, por un servicio y por dinero, ya que funcionan como medio de intercambio, una unidad de cuenta o un depósito de valor.

Cabe precisar que lo antes indicado no se limita a transacciones onerosas, pues también podría darse el caso de una enajenación de criptomonedas a título gratuito, sin que medie contraprestación alguna, no siendo necesaria la obtención de dinero, algún bien o servicio específico.

En suma, el intercambio de criptomonedas queda sujeto a la amplia gama de figuras contractuales para la adquisición y enajenación de bienes, obtención de bienes o servicios.

Sin perjuicio de ello, de manera gráfica podemos anotar que cuando una criptomoneda es intercambiada por dinero, la operación se asemeja a una compraventa de criptomonedas,

(3) Algunos autores como Pérez-Carasa, plantean una distinción de estas actividades en función a los mercados relacionados a los mismos, siendo el "mercado primario" aquel relacionado con el proceso de creación originaria de los Bitcoins y la asignación de los mismos entre los mineros que resuelven correctamente los problemas lógico-matemáticos; y el "mercado secundario" en el cual los bitcoins ya existentes se transmiten entre particulares, bien a cambio de divisas, bien como medio de pago por bienes y servicios adquiridos.

(4) Un caso similar ocurre con aquellos modelos de trabajo denominados "Proof of stake - PoS". 
intercambio de bien por dinero). Por su parte, cuando la criptomoneda es intercambiada por un bien, incluso por otra criptomoneda, la figura atiende a una permuta o trueque, intercambio de bien por bien; mientras que, para el caso de intercambios entre la criptomoneda y un servicio, la operación resulta equiparable a la figura de un pago en especie por el servicio recibido, intercambio de bien por servicio.

Asimismo, si bien podríamos encontrarnos ante un caso de un intercambio simple de criptomonedas por dinero $u$ otros bienes entre dos operadores -lo que tradicionalmente podría recaer en figuras como la compraventa o la permuta de bienes-, también existen casos en los que se presentan figuras que permiten la participación en fondos de inversión que captan recursos de inversionistas para retribuirlos en rentabilidades futuras, por ejemplo. Claro está que ello dependerá exclusivamente de la libre iniciativa privada siempre que esta no se encuentre prohibida.

Ahora bien, con relación a los intercambios realizados con criptomonedas podemos identificar los siguientes agentes intervinientes: (i) las casas de cambio de criptomonedas, (ii) los poseedores de criptomonedas y (iii) los receptores de criptomonedas.

Siguiendo esta distinción, que permite realizar un mejor análisis de las operaciones de intercambio que se realizan con criptomonedas desde una perspectiva del control del cumplimiento tributario, González anota lo siguiente: (i) las casas de cambio son entidades que cambian o facilitan el cambio de criptomonedas entre sí y por dinero; (ii) los poseedores de criptomonedas son aquellos sujetos que han conseguido criptomonedas por cualquier medio de intercambio (ya sea por dinero, servicios y bienes, incluyendo otras criptomonedas), los cuales poseen unas claves o códigos que les permiten realizar intercambios con dinero, bienes y servicios; y (iii) los receptores de criptomonedas son tiendas de comercio electrónico y/o prestadores de servicios que aceptan como medio de pago a las criptomonedas, sin tener obligación alguna para ello (2018, p. 36).

El autor añade que, desde la perspectiva tributaria, las casas de cambio parecerían ser las fuentes más importantes de información simple y fiable en el mercado de criptomonedas, identificándose diversos tipos de agentes como los denominados "Brokers" o "Exchanges" y las plataformas de cambio. En esa línea, Pérez-Carrasa citando a Miras señala que, en la práctica, puede hacerse referencia a tales operadores de la manera que sigue:

En primer lugar, las "casas de cambio", "Exchange houses" o "exchangers": son personas físicas o jurídicas cuya actividad consiste en la compraventa de bitcoins y en la intermediación en dichas transmisiones, para lo cual suelen utilizar diversos soportes, como páginas webs o plataformas virtuales que ponen en contacto a oferentes y demandantes de estas criptomonedas, percibiendo a cambio de su labor una determinada comisión. A modo de ejemplo, podrían asimilarse en su forma de operar a las empresas dedicadas al cambio de divisas.

En segundo lugar, las Ilamadas "trading platforms", que son plataformas de negociación de bitcoins que reúnen a compradores y vendedores de esta y demás criptomonedas y que les proporcionan una plataforma de negociación. Se diferencian de las anteriores en que estas plataformas no compran y venden monedas virtuales por sí mismas, sino que se limitan a poner en contacto oferentes y demandantes (2018, p. 142).

Al respecto, González apunta que, como los "Brokers" o "Exchanges", entre los cuales cita como ejemplos operadores como COINBASE, BITTREX y BISTAMP, admiten el cambio con dinero, se les aplican las reglas de KYC -Know your Customerque son utilizadas en la banca, que son medidas que buscan prevenir el blanqueo de capitales o lavado de dinero; mientras que en las plataformas de cambio- tales como LOCALBITCOINS -anota que, si bien solo ponen en contacto al comprador con el vendedor y se desentienden del resultado final del acuerdo entre ambos, se puede conocer si el vendedor se comportó adecuadamente por las calificaciones que obtiene, pues se cuenta con una ficha actualizada de los comerciantes que indica la fecha en que comenzó a operar, cuántas transacciones ha realizado, la satisfacción de los clientes, entre otros (2018, pp. 40-41).

Por lo expuesto, podemos advertir que la clasificación de los operadores antes señalados -esto es, las casas de cambio de criptomonedas, los poseedores de criptomonedas y los receptores de criptomonedas- resulta didáctica para comprender el alcance de los principales agentes que intervienen en los intercambios de criptomonedas, siendo un foco de atención las casas de cambio, que resultarían una fuente importante de información para efectos del control de estas operaciones en materia tributaria.

Cabe señalar que, en líneas generales, los agentes intervinientes en los intercambios podrían ser tanto personas naturales como personas jurídicas, pues no existe una limitación normativa o fáctica que impida realizar dicha actividad con criptomonedas, 
Perspectivas del derecho fiscal comparado: Criptomonedas, transacciones y eventos impositivos. Tratamiento tributario en el Perú, problemas y recomendaciones

A view from comparative tax law: Cryptocurrencies, transactions and taxable events. Tax treatment in Peru, problems and recommendations

lo que finalmente se soporta en la libertad empresarial, de comercio y la iniciativa privada.

\subsubsection{Mecanismos de inversión alternativos para la adquisición de criptomonedas}

Como punto adicional, tenemos diversos mecanismos de inversión alterativos para la adquisición de criptomonedas, que consisten esencialmente en la captación de recursos de los particulares con el fin de obtener beneficios económicos ante una eventual producción o adquisición de criptomonedas.

Ubaldo González señala que debido al dinamismo del mercado, han emergido activos nuevos como los denominados "Initial Coin Offerings" -o "ICOs"-, los "Forks" (desdoblamiento de un Bitcoin en otras monedas) y los "Tokens" - literalmente, fichas: valores que se pueden intercambiar por bienes o servicios futuros -, por lo que actualmente es común que se utilice la expresión "criptoactivos", un término más amplio que el de criptomonedas (2018, p. 17). Así, el autor apunta que, para tales instrumentos, los problemas de aplicación de las normas generales resultan incluso más complicados que para las monedas virtuales o criptomonedas en general.

Por ejemplo, los ICOs son definidos como un mecanismo innovador de captación de recursos del público, que utilizan instrumentos denominados "coins" o "tokens" -productos que también pueden ser denominados oferta pública de tokens o venta de tokens-, mediante los cuales una empresa o individuo emite "tokens" y los ofrece en una plataforma transaccional, recibiendo como contraprestación monedas de curso legal -como los soles, dólares, euros u otros- o monedas virtuales como las criptomonedas de Bitcoin o Ether ${ }^{(5)}$, siendo un mecanismo alterno al sistema intermediado tradicional constituido por entidades bancarias o el mercado de valores ${ }^{(6)}$.

\subsection{Riesgos potenciales en el uso de criptomonedas}

\subsubsection{Riesgos generales}

Teniendo en cuenta las características de las criptomonedas y los diversos usos que se le puede dar -que carecen de un ente regulador o controlador-, abordaremos aquellas circunstancias riesgosas en el uso de dichas monedas virtuales que han sido advertidas por los estados y diversas instituciones.

De acuerdo a lo señalado por el Grupo de Acción Financiera Internacional, estas monedas virtuales son potencialmente vulnerables al abuso de lavado de activos y la financiación terrorista por muchos de los motivos, siendo uno de los principales que permiten un mayor anonimato que los métodos tradicionales de pago sin efectivo (2015, pp. 34-35). Así, sumado a que las criptomonedas son comercializadas en internet, se podría estar permitiendo la financiación anónima, pues no se identificaría correctamente la fuente del financiamiento.

En efecto, siguiendo las anotaciones de dicha institución, el propio diseño de los sistemas descentralizados de las criptomonedas utiliza direcciones que funcionan como cuentas, por lo que no cuentan con la identificación de los clientes, sus nombres u otro tipo de información. Ello se debe a que, como regla general, los protocolos que enmarcan la operatividad de las criptomonedas no requieren -o proporcionan- la identificación o verificación de los participantes.

Así, toda vez que las criptomonedas pueden ser utilizadas para realizar transferencias o pagos transfronterizos, se dificulta en mayor medida el control sobre las operaciones realizadas por los particulares y complejiza la aplicación de la normativa interna de los Estados, así como su competencia jurisdiccional.

En suma, resulta evidente que la tecnología que soporta las criptomonedas ha generado diversos riesgos en su uso, pues dadas las características del propio sistema -especialmente aquellas relacionadas a la falta de identificación de los sujetos de las transacciones, el alto grado de anonimato y la ausencia de un ente supervisor-, se genera un espacio de difícil alcance para el control e intervención de los Estados -como la lucha contra el lavado de activos-, lo que incluso ya venía siendo un desafío para las jurisdicciones en el sistema tradicional.

(5) Véase Chavarría, D. (2020). Surgimiento de las ICOS: implicaciones para el caso colombiano. Revista de Derecho Privado, 38. https://docplayer.es/208374613-Surgimiento-de-las-icos-implicaciones-para-el-caso-colombiano.html. Asimismo, véase Hernandez, J. (2018). Criptomonedas y Aplicación en la Economía. Universidad Pontificia ICAI-ICADE, Business School, https://repositorio. comillas.edu/rest/bitstreams/210001/retrieve

(6) Para mayor información, véase los informes emitidos por la Organización para la Cooperación y el Desarrollo Económicos (OECD por las siglas en inglés de u "Organisation for Economic Co-operation and Development"): Initial Coin Offerings (ICOs) for SME Financing en www.oecd.org/finance/initial-coin-offerings-for-sme-financing.htm. Asimismo, véase OECD work on SME Financing en www.oecd.org/finance/sme-financing.htm. 


\subsubsection{Riesgos en el ámbito tributario o fiscal}

Las características de las criptomonedas y su utilización en el mercado actual generan diversas situaciones de riesgo inminente en el ámbito tributario o fiscal, las que se encuentran generalmente vinculadas a la evasión fiscal y el incumplimiento de obligaciones tributarias.

Así, como bien anotamos en el punto anterior, las principales características que incrementan el riesgo en perjuicio del fisco giran en torno al alto grado de anonimato en las transacciones que se pueden realizar mediante el uso de las criptomonedas ${ }^{(7)}$, la ausencia de un ente supervisor y el elevado nivel de volatilidad respecto a su valor o precio.

Como bien identifica Ubaldo González, existen diversas situaciones que evidencian la existencia de los riegos fiscales inherentes a las criptomonedas, siendo las más relevantes las siguientes:

a) La falta de información sobre la sujeción de las operaciones dificulta el cumplimiento voluntario.

b) Las dudas surgidas respecto a la caracterización y calificación jurídica de las criptomonedas pueden causar que, incluso siendo el contribuyente consciente de la obligación de contribuir, no sepa cómo hacerlo.

c) En relación a las plusvalías en criptomonedas resulta difícil acreditar el valor razonable de la moneda virtual, ya que no existen mercados organizados.

d) Las obligaciones de declaración relativas a terceros -como las establecidas a las plataformas de intercambio entre particulares- se enfrentan a la dificultad de establecer un valor cierto e incluso de poder identificar a las partes de la transacción, dado el anonimato inherente a las monedas virtuales.

e) Son un medio idóneo para instrumentar el fraude fiscal, pues los sistemas de criptomonedas no requieren que los participantes tengan que identificarse, lo que ofrece un alto potencial como instrumentos para la evasión, especialmente en transacciones transfronterizas (2018, p. 25).

Como se observa, existen circunstancias que suponen un alto riesgo de elusión fiscal e incumplimiento tributario debido a la realización de operaciones con criptomonedas, las cuales evidencian una necesaria adopción de medidas por parte de los Estados, ya sea de carácter inductivo o regulatorio.

Por otro lado, tenemos que el valor de las criptomonedas tiene un alto nivel de volatilidad -incluso en un corto tiempo-, lo que ocasiona que la valoración de las transacciones realizadas sea compleja, y, en ese sentido, que exista un alto riesgo de pérdida de recaudación ante acciones que pretendan reducir las bases tributarias o imponibles en operaciones gravadas, ya sea en tributos sobre la renta, el valor agregado -o consumo- e incluso aquellos que recaen sobre el patrimonio.

Consideramos que las dificultades para la determinación del precio de una criptomoneda parten de la ausencia de alguna entidad que respalde su valor - como podría ser un ente regulador o supervisor- lo que implica que la valoración de las criptomonedas se rija básicamente por reglas de oferta y demanda en el ámbito privado, lo que otorga un alto margen de actuación a los particulares.

Ello es un tema complejo pues, por citar un caso, es de conocimiento que incluso las propias plataformas de intercambio establecen precios diferentes para una misma criptomoneda en un determinado momento, debido a que su valoración se basa en complejos registros de precios de compra y venta. Lo dicho genera muchas dificultades al momento de registrar operaciones, además del esfuerzo que implica mantener la información de tales precios durante un largo período de tiempo, especialmente si se cuenta con distintos tipos de criptomonedas, o en caso de tener un mismo tipo de criptomonedas, si se adquieren en diversas fechas a diferentes precios.

\section{Tratamiento jurídico de las criptomonedas y sus implicancias para el sistema tributario en la legislación comparada}

\begin{abstract}
A continuación, procederemos a exponer de manera resumida el tratamiento jurídico de las criptomonedas en la legislación comparada y las implicancias que ello supone en materia tributaria. Este punto tiene como objeto detallar el panorama actual de la evolución normativa que han seguido diversos países y su avance frente a la lucha contra la evasión fiscal y el incumplimiento tributario que conlleva el uso de criptomonedas.
\end{abstract}

(7) Véase OECD. (2019). Lavado de activos y financiación del terrorismo - Manual para inspectores y auditores fiscales (pp. 55-58). https://www.oecd.org/ctp/crime/lavado-de-activos-y-financiacion-del-terrorismo-manual-para-inspectores-y-auditores-fiscales.pdf 
Perspectivas del derecho fiscal comparado: Criptomonedas, transacciones y eventos impositivos. Tratamiento tributario en el Perú, problemas y recomendaciones

A view from comparative tax law: Cryptocurrencies, transactions and taxable events. Tax treatment in Peru, problems and recommendations

Para tales efectos, se hará referencia en general a las actividades de minería y el intercambio de criptomonedas siguiendo los términos expuestos anteriormente y enfocándonos en los agentes que intervienen en cada una de ellas; $y$, a su vez, se tomará en cuenta para el análisis tributario, el tratamiento impositivo de dichas situaciones en los impuestos que recaen sobre la renta, el consumo -o valor agregado- y el patrimonio, de ser el caso.

\subsection{Restricción de actividades con criptomonedas y su implicancia en la tributación}

Bien es sabido que algunos países han tomado medidas encaminadas a prohibir o restringir el intercambio de criptomonedas con el objeto de cautelar los riesgos inherentes a su uso, dada las características que le otorga la tecnología "blockchain" y su autonomía frente a las instituciones tradicionales propias de un Estado que regulan o supervisan la actividad financiera y monetaria del país.

Según el informe emitido por la Organización para la Cooperación y el Desarrollo Económicos (en adelante, "OECD" por las siglas en inglés de Organisation for Economic Co-operation and Development) denominado "Taxing Virtual Currencies: An Overview of Tax Treatments and Emerging Tax Policy Issues" (en adelante, "el informe de la OECD"), las prohibiciones o restricciones que se han regulado en cierto recae en determinadas actividades que forman parte de la creación y el intercambio de criptomonedas, las cuales se podrían clasificar de la siguiente manera:

a) Prohibición general: Se prohíbe el uso y/o cualquier transacción de criptomonedas, esto es, se encuentra prohibido la compra y venta de criptomonedas y su utilización como medio de pago. Este es el caso de Bangladesh, Bolivia, Marruecos, Nepal, Macedonia del Norte, Lesoto, Rusia y Arabia Saudita. Cabe señalar que países como Algeria incluso han dispuesto expresamente que incluso la tenencia de criptomonedas es ilegal.

b) Prohibición de plataformas de negociación comercial: Se prohíbe el funcionamiento de plataformas de comercialización de criptomonedas -trading o intercambio-. Este es el caso de China.

c) Prohibición del uso de criptomonedas como medio de pago: Se prohíbe la compra y venta de bienes y servicios con criptomonedas. Este es el caso de Ecuador e Indonesia.

d) Prohibición de ICOs: Se prohíbe la operatividad de ICOs. Este es el caso de China y Corea.

e) Restricción en el sector financiero: Se prohíbe a las instituciones financieras reguladas participar en actividades relacionadas a las criptomonedas e impulsar directa o indirectamente a personas o empresas a la realización de tales actividades. Este es el caso de Camboya, China, Colombia,
República Dominicana, Jordania, Irán, Kuwait, Qatar, Lituania, Macao, Tailandia (Organisation for Economic Co-operation and Development [OECD], 2020, pp. 1718).

En términos generales, los países que regulan prohibiciones o restricciones se encuentran vinculados a las actividades de intercambio de criptomonedas, es decir, aquellas en las que se emplea la criptomoneda como método de pago para la obtención de bienes o servicios, o para obtener dinero u otra criptomoneda a cambio.

Del mismo modo, dicha limitación atiende a los agentes intervinientes: los poseedores de criptomonedas -cualquier sujeto que tenga criptomonedas que pretenda intercambiarlay sus posibles receptores -cualquier entidad que venda bienes o preste servicios que reciba criptomonedas como medio de pago-. También alcanza a las casas de cambio de criptomonedas -entidades que se encargan de promover el intercambio de criptomonedas por dinero o entre distintas criptomonedas- $e$ incluso a las plataformas de negociación comercial.

Ahora bien, atendiendo a este marco regulatorio restrictivo de operaciones y agentes, cabe peguntarnos sobre las implicancias tributarias que conllevaría la realización de actividades relacionadas a las criptomonedas que se encuentren prohibidas o restringidas.

Al respecto, podemos indicar que, ante la ausencia de una norma expresa que regule dicha situación en materia tributaria, nos encontraríamos ante la eventual disyuntiva de determinar si las actividades ilícitas podrían tener efecto tributario o no, en tanto atienden a situaciones jurídicas particulares; lo que en buena cuenta podría resumirse en que, por un lado, sí correspondería atender a su tributación en atención al principio de capacidad contributiva y el deber de contribuir como instituciones de una rama del derecho independiente del ordenamiento jurídico, y por otro, que no correspondería dicho 
tratamiento, en tanto el Estado no podría amparar ninguna conducta ilícita ${ }^{(8)}$.

\subsection{Tratamiento jurídico de las criptomonedas como una moneda de curso legal y sus implicancias en la tributación} Como regla general, tenemos que para la mayoría de países del mundo, las criptomonedas no califican jurídicamente como una moneda de curso legal debido a que no cumplen con las características esenciales de una moneda, en tanto no es emitida por una entidad pública o estatal, no es de aceptación obligatoria y con plenos efectos cancelatorios en su jurisdicción, y no responde a la confianza generada por el respaldo de un Estado soberano o alguna materia prima subyacente que le otorgue un valor intrínseco (OECD, 2020, pp. 18-19).

Sin embargo, debe tenerse presente que, en materia del Impuesto al Valor Agregado (en adelante, "IVA"), la mayoría de los países de la Unión Europea y otros países de la región han adoptado como criterio para tales efectos impositivos, asemejar el tratamiento tributario aplicable a las monedas de curso legal a las transacciones con criptomonedas, esto es, considerar a las criptomonedas como divisas. En efecto, ello se basa en el razonamiento establecido por el Tribunal de Justicia en la sentencia (Decisión Prejudicial) recaída en el Asunto C-264/14 emitida en el año 2015(9), en la cual se resolvió que el cambio de unidades de la criptomoneda "Bitcoin" por divisas tradicionales -monedas de curso legal- se encontraba exento del IVA, criterio que tuvo como directriz garantizar la neutralidad fiscal y, a su vez, aliviar las dificultades para la determinación de la base imponible y las respectivas deducciones en materia del IVA. En ese sentido, dicho Tribunal consideró que las criptomonedas eran comparables a las monedas fiduciarias -o de curso legal- en la medida en que su única finalidad era proporcionar un medio de cambio.

Ahora bien, a pesar de que el criterio antes expuesto resultaba un análisis del caso en concreto en materia del IVA, algunos pocos países como Bélgica, Costa de Marfil, Polonia e Italia, consideraron aplicable dichos lineamientos para todo efecto tributario. Es decir, en estas jurisdicciones se asemeja las operaciones que utilizan criptomonedas a las transacciones realizadas con una moneda de curso legal para efectos impositivos, tanto en materia de impuestos al valor agregado como también para impuestos sobre la renta (OECD, 2020, p. 23).

Por ejemplo, en el caso de Italia, la administración tributaria de dicho país ${ }^{(10)}$ ha señalado que ante la ausencia de una legislación especial aplicable a las criptomonedas debe tomarse como punto de referencia el pronunciamiento del Tribunal de Justicia, siendo que la actividad de intermediación de monedas tradicionales con bitcoins -realizada de forma profesional y habitual- constituye una operación relevante para todo efecto impositivo, y no solo para el IVA. En tal sentido, indica que, en materia de imposición directa, una empresa debería reconocer los efectos tributarios -ganancia o pérdida- por la diferencia obtenida de los intercambios de criptomonedas por dinero, esto es, aquellos relacionados a mandatos de compra o venta de criptomonedas por parte de clientes en los cuales la empresa realiza una función de intermediaria.

Finalmente, es preciso señalar el caso particular de El Salvador, lugar que se ha convertido en el primer país del mundo en dar los primeros pasos para el reconocimiento legal de una criptomoneda ${ }^{(11)}$-en concreto, el Bitcoincomo una moneda de curso legal, adoptando mediante el Decreto 57 de fecha 09 de junio de $2021^{(12)}$, algunas disposiciones que vale la pena mencionar.

Según el Dictamen favorable de la Comisión Financiera de la Asamblea Legislativa del 08 de junio de 2021(13), resultaba necesario establecer un marco regulatorio para el tratamiento del Bitcoin

(8) Véase De Mosteyrín, R. (2017). Tributación de las ganancias que se obtienen del ilícito penal. Foro - Revista de ciencias jurídicas y sociales Nueva Época, 20, 93-126. https://revistas.ucm.es/index.php/FORO/article/view/57531

(9) Véase el pronunciamiento en el sitio web de la Unión Europea - "EUR-Lex". https://eur-lex.europa.eu/legal-content/es/ TXT/?uri=CELEX:62014CJ0264.

(10) Véase Risoluzione 72 emitida por la Agenzia Entrate en el portal web del Ministero dell'Economia e delle finanze de Italia, https://www.agenziaentrate.gov.it/portale/documents/20143/302984/Risoluzione+n.+72+del+02+settembre+2016_ RISOLUZIONE+N.+72+DEL+02+SETTEMBRE+2016E.pdf/8e057611- 819f-6c8d-e168-a1fb487468d6

(11) Véase El Salvador, primer país del mundo en reconocer al Bitcoin como moneda de curso legal en el sitio web de la Nueva Asamblea Legislativa de El Salvador. https://www.asamblea.gob.sv/node/11282

(12) Véase el Decreto 57 en el sitio web de La Nueva Asamblea. https://www.asamblea.gob.sv/sites/default/files/documents/ decretos/8EE85A5B-A420-4826-ABD0-463380E2603B.pdf

(13) Véase el Dictamen 3 de la Comisión Financiera de la Asamblea Legislativa de fecha 08 de junio de 2021 en el sitio web de la Nueva Asamblea Legislativa de El Salvador. https://www.asamblea.gob.sv/sites/default/files/documents/dictamenes/27F0BD6F-3CEC4F52-8287-432FB35AC475.pdf 
Perspectivas del derecho fiscal comparado: Criptomonedas, transacciones y eventos impositivos. Tratamiento tributario en el Perú, problemas y recomendaciones

A view from comparative tax law: Cryptocurrencies, transactions and taxable events. Tax treatment in Peru, problems and recommendations

como una moneda de curso legal para facilitar la inclusión financiera e impulsar el crecimiento económico, por lo que se estableció, en el artículo 1 de dicho dictamen, el reconocimiento legislativo del Bitcoin "como moneda de curso legal, irrestricto con poder liberatorio, ilimitado en cualquier transacción y a cualquier título que las personas naturales o jurídicas públicas o privadas requieran realizar".

Así, la norma dispone que el tipo de cambio entre el Bitcoin y el dólar será establecido libremente por el mercado, que todo precio podrá ser expresado en Bitcoin y que todo agente económico deberá aceptar Bitcoin como forma de pago cuando así le sea ofrecido por quien adquiere un bien o servicio. Asimismo, señala que, para fines contables, se utilizará el dólar como moneda de referencia y que todas las contribuciones tributarias podrán ser pagadas en Bitcoin.

Cabe advertir que, en el ámbito tributario, su artículo 5 dispone expresamente que "los intercambios en bitcoin no estarán sujetos a impuestos sobre las ganancias de capital al igual que cualquier moneda de curso legal", por lo que resulta claro que el tratamiento impositivo en materia de impuesto a las rentas se equipara jurídicamente al de las monedas de curso legal.

De lo antes expuesto, podemos notar que el tratamiento tributario de una criptomoneda considerada como una moneda de curso legal para efectos impositivos -principalmente para efectos de impuestos al valor agregado e impuestos sobre la renta- implicaría asemejar en todo aspecto las criptomonedas como dinero, por lo que eventualmente podría recurrirse al tratamiento tributario aplicable a las actividades desarrolladas por entidades financieras o casas de cambio de divisas, e incluso, incidir en reglas del reconocimiento de resultados obtenidos por la diferencia de cambio en operaciones en moneda extranjera, por ejemplo.

\subsection{Tratamiento jurídico de las criptomonedas como bienes y sus implicancias en la tributación}

Teniendo en cuenta que, como regla general, las criptomonedas no califican como una moneda de curso legal, la normativa aplicable en primera instancia es aquella que regula la situación jurídica de los "bienes", que normalmente se encuentran regulados en el ámbito civil patrimonial. Debe indicarse que las criptomonedas son bienes incorporales, intangibles o inmateriales, pues su existencia radica básicamente en la red y la tecnología que se emplea para resguardar su funcionamiento.

El informe de la OECD señala que, en la mayoría de los casos, los países consideran a las criptomonedas como una forma de "property" para fines fiscales. Así, detalla que existen diversas posiciones sobre su tratamiento en particular: criptomonedas como activos intangibles diferente al goodwill (Australia, France, Chile, Republica Checa, España, Nigeria, Reino Unido), criptomonedas como commodities (Austria, Canadá, China, Indonesia), criptomonedas como instrumentos financieros (Brasil, Dinamarca, Israel, Japón, Sudáfrica), entre otros (2020, p. 15).

En esa línea, el tratamiento tributario que recaiga sobre dichos bienes sería, en principio, aquel aplicable para cualquier bien jurídico intangible, con excepción de las situaciones que encuentren sustento jurídico en alguna regulación tributaria especial.

Resulta importante tener en cuenta que para efectos tributarios, un tema de suma importancia es la relación que existe con la contabilidad y los registros contables, siendo que las legislaciones emplean términos, conceptos y criterios de dicha materia para dar lectura y contenido a la normativa tributaria, especialmente en impuestos a la renta, sobre todo para la renta empresarial, y el valor agregado, para el control y registro de operaciones mediante la emisión de comprobantes de pago y el uso de libros y registros contables.

Sin pretender ahondar sobre el tema, cabe mencionar que el informe de la OECD adopta la siguiente postura: ante la ausencia de un pronunciamiento institucional sobre la clasificación de las criptomonedas para fines contables, resultan aplicables los principios generales de contabilidad, según los cuales se realizará su clasificación en función a sus propiedades económicas. Así, se tiene que, por regla general, las criptomonedas serían consideradas como activos intangibles; no obstante, reconoce que la dificultad que supondría encajarla en alguno de los tipos de activos existentes (2020, p. 15).

En esa línea, un criterio particular es el emitido por el Comité de Interpretaciones de las Normas Internacionales de Información Financiera (CINIIF), que ha indicado que las criptomonedas cumplen con la definición de activo intangible según la NIC 38, al calificar como un activo identificable de carácter no monetario y sin apariencia física. En esa línea, señala que cumple con la definición de activo intangible pues: "(a) it is capable of being separated from the holder and sold or transferred individually; and (b) it does not give the holder a right to receive a fixed or determinable number of units of currency". Asimismo, precisa que no calificarían como activos financieros o efectivo; y que, 
eventualmente, podrían contabilizarse como parte del inventario cuando una entidad las mantenga como activos para la venta en el curso habitual de sus actividades comerciales, criterio que aplicaría esencialmente para los corredores y comerciantes de criptomonedas (OECD, 2020, pp. 15-16) ${ }^{(14)}$, término similar al que usamos al referirnos a las casas de cambio.

Ahora bien, tomando en consideración estos aspectos, desarrollaremos brevemente el tratamiento tributario aplicado en algunos países sobre la actividad de minería y el intercambio de criptomonedas, haciendo referencia a su incidencia en los impuestos sobre la renta, el consumo o valor agregado y el patrimonio.

\subsubsection{Implicancias tributarias en materia de impuestos sobre la renta y cuestiones problemáticas}

\section{A) Intercambio de criptomonedas}

Como hemos señalado, las criptomonedas pueden ser intercambiadas tanto por dinero, como por bienes -incluidas otras criptomonedas- y servicios. Ahora bien, en la mayoría de países, todos estos intercambios de bienes generan hechos gravados; sin embargo, cabe hacer algunas precisiones al respecto.

En primer lugar, a efectos ilustrativos, debemos tener presente que los efectos tributarios en materia de impuesto a la renta impactan al sujeto o agente poseedor de la criptomoneda que la enajena y que recibe producto de dicha enajenación, un ingreso gravado con el impuesto, ya sea en dinero o en especie, como podría ser un bien o un servicio. Así, un caso particular sería el caso de la permuta de bienes, intercambio de bien por bien, entre los cuales podrían estar la propia criptomoneda, en la que coexistirian dos operaciones de enajenación de bienes con efectos tributarios independientes.

En segundo lugar, resulta importante identificar si el intercambio proviene de una actividad empresarial o no, ya que, si nos encontramos ante una actividad empresarial, el término de ingreso o renta gravable resulta más amplio, mientras que para el caso de una actividad personal u ocasional no, por lo que se recurriría necesariamente al concepto de ganancia de capital por enajenación de bienes -claro está- por la enajenación de la criptomoneda. Dicho esto, resulta evidente que tal distinción tendría relevancia en personas naturales que no cuentan con un negocio o actividad empresarial, pues como regla general, si fueran personas jurídicas, su tratamiento siempre sería el de una actividad empresarial.

Para efectos de verificar si una actividad de intercambio podría resultar de carácter empresarial o no, podemos citar casos particulares como lo que sucede en Italia, país en el cual se evidenciaría una actividad empresarial en la medida que las transacciones en criptomonedas tengan un carácter especulativo, siendo que en tales casos se sujetarían a las reglas para rentas provenientes del comercio de monedas fiduciarias extranjeras (OECD, 2020, p. 28). De manera similar sucede en Canadá, según la cual, cuando una criptomoneda se adquiere con ánimo de lucro, se entiende que los intercambios realizados con ella constituyen una actividad empresarial (OECD, 2020, p. 30).

Otro criterio interesante lo podemos apreciar en el caso de España. Según PérezCarasa, la transmisión de criptomonedas por personas naturales es llevada como una actividad profesional -"exchangers" persona física- que califica como rendimiento de actividades económicas ${ }^{(15)}$, cuando se observa que en su realización se utilizan diversos soportes, como páginas webs o plataformas virtuales que ponen en contacto a oferentes y demandantes de estas criptomonedas percibiendo a cambio de su labor una determinada comisión, pues evidencia que dicho rendimiento procede

(14) Para un análisis más detallado que aborda el tratamiento contable de las criptomonedas, véase Chirinos, A. (2020). Regulación y tributación en el mercado de criptoactivos, una perspectiva de derecho comparado. Revista de la Facultad de Derecho de Montevideo UDELAR, 48. https://revista.fder.edu.uy/index.php/rfd/article/view/722

(15) Al respecto, cabe señalar que el artículo 27 de la Ley 35/2006 del "Impuesto sobre la Renta de las Personas Físicas y de modificación parcial de las leyes de los Impuestos sobre Sociedades, sobre la Renta de no Residentes y sobre el Patrimonio" establece lo siguiente: "Artículo 27. Rendimientos íntegros de actividades económicas.

1. Se considerarán rendimientos íntegros de actividades económicas aquellos que, procediendo del trabajo personal y del capital conjuntamente, o de uno solo de estos factores, supongan por parte del contribuyente la ordenación por cuenta propia de medios de producción y de recursos humanos o de uno de ambos, con la finalidad de intervenir en la producción o distribución de bienes o servicios.

En particular, tienen esta consideración los rendimientos de las actividades extractivas, de fabricación, comercio o prestación de servicios, incluidas las de artesanía, agrícolas, forestales, ganaderas, pesqueras, de construcción, mineras, y el ejercicio de profesiones liberales, artísticas y deportivas (...)". 
Perspectivas del derecho fiscal comparado: Criptomonedas, transacciones y eventos impositivos. Tratamiento tributario en el Perú, problemas y recomendaciones

A view from comparative tax law: Cryptocurrencies, transactions and taxable events. Tax treatment in Peru, problems and recommendations

de trabajo personal y/o del capital, y dado que existe una ordenación por cuenta propia de medios de producción y/o recursos humanos con el fin de intervenir en la producción o distribución de bienes y servicios (2018, p. 147).

Por lo tanto, retomando a la idea inicial, queda claro que para algunas jurisdicciones es importante determinar si el intercambio proviene de una actividad empresarial o no, pues tal como sucede en Portugal, los intercambios de criptomonedas no encajan en la definición de ganancia de capital, por lo que dichas operaciones no generan rentas gravadas en ese supuesto, salvo que estas se realicen como parte de una actividad empresarial (OECD, 2020, p. 27).

No obstante, también existen casos en donde esta distinción resulta irrelevante, debido a que en algunos países los intercambios si califican como ganancias de capital. En efecto, en Polonia los ingresos provenientes de los intercambios de criptomonedas por dinero, o cuando se utilizan como pago para la adquisición de otros bienes y servicios, se tratan como ganancias de capital -independientemente de si son provenientes de una actividad comercial o personal- y están sujetos a la tasa impositiva respectiva (OECD, 2020, p. 28).

Mención aparte merece el criterio que aplican ciertos países respecto al intercambio entre criptomonedas -intercambio de bien por bien-, pues en jurisdicciones como Chile, Francia, Letonia y Polonia, dicho intercambio no se encuentra gravado debido a razones netamente pragmáticas, es decir, para evitar las dificultades que conlleva establecer el valor monetario entre dos criptomonedas o para fomentar su comercio (OECD, 2020, p. 28).

Finalmente, como bien indicamos, es preciso reiterar que el intercambio entre criptomonedas por bienes o servicios -que incluye también a los salarios- son tratadas como trueques o transacciones recíprocas para efectos fiscales en casi todos los países encuestados en el informe de la OECD, siendo que la enajenación de la criptomoneda da lugar a un hecho imponible para el propietario de la misma, mientras que para el receptor de la criptomoneda -que la recibe como medio de pago por un bien, servicio o salario- dicha circunstancia no cambia el tratamiento fiscal subyacente que se habría aplicado si la compra se hubiera realizado en moneda de curso legal. En consecuencia, un proveedor que recibe criptomonedas como pago por la venta de bienes o prestación de servicios estaría obligado a incluir el valor de las criptomonedas recibidas en su renta imponible, razonamiento que también aplica para el caso de los salarios pagados en criptomonedas (OECD, 2020, p. 30).

\section{B) Actividad de minería}

Como bien hemos indicado, la actividad de minería constituye un procedimiento informático para la obtención de la criptomoneda, por lo que el ingreso o renta gravable que retribuye dicha actividad será la propia obtención de criptomonedas. En buena cuenta, esto resulta equiparable a un mecanismo para la adquisición de un bien en propiedad.

Al respecto, Zocaro advierte dos posiciones sobre la naturaleza de la actividad de minería en Argentina, señalando que, por un lado, están aquellos que la consideran como un "servicio" prestado a la red y, por el otro, los que sostienen que no es un servicio, sino que en realidad es un proceso de "creación" de un bien inmaterial. El autor detalla:

Si se considerase la primera opción, la retribución en criptomonedas que el minero recibiese por su "servicio" estaría alcanzada en el impuesto a las ganancias (...). Por otra parte, los que sostienen la idea de que la minería es un proceso de "creación" de un bien inmaterial opinan que la red blockchain no es la que crea nuevas unidades de la criptomoneda de que se trate para luego "otorgárselas" al minero correspondiente, sino que es ese minero el que "registra" la información en el nuevo bloque y por lo tanto él mismo está creando nuevas criptomonedas. Y si se tomase como válida esta postura, se tributaría ganancias recién al momento de la venta, y no por el minado en sí (2020, pp. 32-33).

En segundo lugar, cabe advertir que la actividad de minería podría ser producto de una actividad personal -con fines personales u ocasionales- o de una actividad empresarial -con carácter habitual y propias de un negocio-, lo cual podría tener impacto no solo para determinar la base imponible, sino incluso para verificar si un hecho se encuentra gravado o no. Veamos:

Según el informe de la OECD, para algunos países, la obtención de criptomonedas como resultado de la actividad de minería se encuentra sujeta al impuesto que grava la renta debido a que se considera que dicha adquisición califica como un "ingreso" - "income", "other capital income" o "miscellaneous income"- al valor de la unidad, otorgándose la posibilidad de deducir los costos asociados con su obtención, tales como los costos de electricidad y equipos utilizados en la minería (2020, p. 24). 
Por ejemplo, en Noruega, los ingresos (income) procedentes de la minería se calculan en función del valor de mercado de la criptomoneda recibida en el momento de la "extracción", pues se consideran ingresos imponibles procedentes de activos (taxable income from "assets"). Asimismo, en el Reino Unido, los ingresos (income) procedentes de la minería se consideran hechos imponibles al momento de la recepción de las criptomonedas, tanto si son percibidos por personas físicas (miscellaneous taxable income) como en el curso de una actividad comercial (trading profits), y se estiman al valor de la unidad de la criptomoneda en libras esterlina en dicha oportunidad (OECD, 2020, pp. 24-25).

Asimismo, existen otras jurisdicciones en las que para determinar si la adquisición de criptomonedas se encuentra gravada o no, resulta importante identificar si la actividad se considera como una actividad personal o empresarial, pues en estos casos, la adquisición de criptomonedas producto de la minería solo supondría un hecho gravado cuando provenga de una actividad empresarial(16), mas no cuando dicha obtención resulte de una actividad personal u ocasional. Este sería el caso de países como Australia, Canadá, Alemania, Hong Kong (China), Luxemburgo, Singapur, Suiza y Suecia (OECD, 2020, pp. 25-26).

Cabe señalar que para diferenciar si una actividad califica como empresarial o no, se podría tener como referencia el criterio empleado en Singapur: si una persona realiza el minado como un pasatiempo(17) esta calificaría como una actividad personal u ocasional, mientras que si se verifica un esfuerzo habitual y sistemático para obtener mayores beneficios, ello podría implicar una actividad empresarial.

Finalmente, una opinión particular para el caso de España es lo señalado por Pérez-Carasa, que sostiene lo siguiente: Dado que la obtención de Bitcoins proviene de la realización de una actividad personal y que "dicha actividad se lleva a cabo de forma profesional y por cuenta propia -esto es, sin mantener ninguna relación de dependencia con un tercero-, parece razonable calificar este tipo de rentas como rendimientos de actividades económicas", más aun si se tiene en cuenta que para que la actividad de minería sea rentable y eficiente se requiere de una importante cantidad de medios y equipos informáticos, por lo que resulta frecuente que los mineros se coordinen y organicen en redes llamadas "pools" o incluso que se lleve a cabo esta actividad a través de sociedades con equipos especializados llamadas "granjas de servidores". (2018, p. 145).

\subsubsection{Implicancias tributarias en materia de impuestos al valor agregado y cuestiones problemáticas}

\section{A) Intercambio de criptomonedas}

En contraste con la imposición sobre la renta, el tratamiento tributario en materia del IVA se encuentra más generalizado, siendo que los países tienden a tratar las criptomonedas como si fueran monedas de curso legal a pesar de que tengan la calidad de bienes, salvo que la propia ley disponga lo contrario, esto es, se tratan a las criptomonedas como si fueran medios de pago en transacciones que implican su intercambio o enajenación, tal como se ha explicado en un punto anterior.

Ahora bien, este tratamiento se debe principalmente a su pragmatismo, pues para estos efectos existen ciertas complicaciones al tratar jurídicamente a las criptomonedas como bienes cuyas transferencias -enajenacionesse sujeten a reglas del trueque, permuta o "barter transactions", tales como son la falta de un tipo de cambio determinado, la complejidad en verificar el cumplimiento de los intercambios de criptomonedas, el anonimato, la determinación del lugar de la "entrega" de los bienes, el riesgo de fraude, entre otros (OECD, 2020, p. 32).

Dicho esto, en general podemos concluir que los intercambios de criptomonedas por dinero $u$ otras criptomonedas, y -a su vez- los intercambios de criptomonedas por bienes y servicios, no constituyen un hecho gravado en materia del IVA desde el enfoque de la enajenación de la criptomoneda; es decir, la propia actividad de intercambio de criptomonedas -como enajenación de un bien jurídico- cuya contraprestación sea dinero, otras criptomonedas, bienes o servicios, no sería un hecho imponible.

Cabe agregar que lo dicho no implica necesariamente un tratamiento similar para otros servicios relacionados a dichos intercambios -como el "online wallet services"

(16) A manera de ejemplo, en el caso de Suiza, en caso de las rentas empresariales, los ingresos producto de criptomonedas se considerarían como parte del activo.

(17) Un ejemplo de ello podría ser el criterio utilizado en Noruega, en el que, si una persona realiza minado a pequeña escala en una computadora personal desde casa, normalmente esta no calificaría como una actividad empresarial. 
Perspectivas del derecho fiscal comparado: Criptomonedas, transacciones y eventos impositivos. Tratamiento tributario en el Perú, problemas y recomendaciones

A view from comparative tax law: Cryptocurrencies, transactions and taxable events. Tax treatment in Peru, problems and recommendations

o los propios servicios que permiten el acceso para el intercambio de criptomonedas en diversas plataformas-, los que podrían tener un tratamiento particular como un servicio gravado.

De igual modo, debe tenerse en cuenta que las operaciones de venta de bienes y prestación de servicios que sean sujetos al IVA no se ven afectados por el tratamiento antes expuesto cuando estos sean pagados con criptomonedas, pues seguirán siendo ventas y servicios gravados con el impuesto. Por ejemplo: en Reino Unido, los intercambios de criptomonedas quedan fuera del ámbito de aplicación del IVA, aunque dicho tributo resulta exigible por la entrega del bien o servicio por el que se intercambian las criptomonedas. De igual modo, en Suiza, las transacciones con criptomonedas se encuentran fuera del ámbito de aplicación del IVA en caso se intercambien por otras criptomonedas o por monedas de curso legal, mientras que, si se realizan intercambios por otros bienes y servicios, solo se encontrarán sujetos al IVA la entrega del bien o servicio gravados con el impuesto (OECD, 2020, p. 37).

\section{B) Actividad de minería}

Para el caso de la actividad de minería, el tratamiento tributario en materia del IVA sigue los mismos planteamientos esbozados en el punto anterior, pues nos encontramos ante una actividad retribuida con criptomonedas, lo que supone la adquisición de criptomonedas como retribución a dicha actividad.

Sobre el particular, tenemos que en algunos países de la Unión Europea, tales como Alemania, Irlanda, Eslovenia y Suecia, la actividad de minería se encuentra fuera del ámbito de aplicación del IVA, ya que se considera que la recompensa -esto es, la adquisición de criptomonedas- obtenida por dicha actividad y el valor de la operación no se encuentran suficientemente relacionados, pues no se logra determinar una vinculación clara entre el pago recibido y la actividad realizada, sobre todo por el hecho de que realizar la actividad de minería no implica necesariamente la obtención del beneficio o adquisición de criptomonedas -dado que no en todos los casos se logra obtener el resultado favorable, esto es, la consolidación del códigos para la obtención de una criptomoneda por ejemplo-y además, que resulta complejo equiparar el esfuerzo invertido por el minero para dicha actividad y la contraprestación obtenida para ello, en caso se obtenga el resultado positivo(18) (OECD, 2020, pp. 35-36).

En esa línea, García-Torres anota algunas cuestiones importantes a tener en cuenta respecto a la actividad de minería, ya que evidencia diferencias importantes con relación a la prestación de un servicio:

(...) las operaciones de minado de Bitcoins son aquellas que permiten crear nuevos bloques de los que se derivan nuevos Bitcoins y que son remunerados por el sistema con una cantidad de Bitcoins. Pues bien, la actividad de minado no conduce a una situación en la que exista una relación entre el proveedor del servicio y el destinatario del mismo y en los que la retribución abonada al prestador del servicio sea el contravalor del servicio prestado, de tal forma que en la actividad de minado no puede identificarse un destinatario o cliente efectivo de la misma, en la medida que los nuevos Bitcoins son automáticamente generados por la red. En consecuencia, la falta de una relación directa entre el servicio prestado y la contraprestación recibida en los términos señalados, los servicios de minado no estarán sujetos al IVA (2018, p. 88).

En suma, queda claro para el autor que al no existir una relación entre proveedor de un servicio y el destinatario o cliente del mismo debido a que las criptomonedas son generadas por el propio sistema, la actividad de minado no generaría un supuesto de servicio sujeto al IVA; razonamiento similar al expuesto por las administraciones tributarias antes citadas.

\subsubsection{Implicancias tributarias en materia de impuestos sobre la propiedad o el} patrimonio y cuestiones problemáticas

Como bien hemos señalado, las criptomonedas califican como bienes, por lo que podrían encontrarse sujetas a impuestos sobre la propiedad o el patrimonio.

Según el Informe de la OECD, existen jurisdicciones en donde dicha calificación tendría efectos impositivos en tributos que gravan el patrimonio, herencias, donaciones, u otros. Así, por ejemplo, se tiene que el Reino Unido considera a las criptomonedas como bienes para efectos del "Inheritance Tax" -impuesto sobre las herencias o sucesiones-, y, de igual manera, en Finlandia, las criptomonedas recibidas por herencia se encuentran sujetas a tales impuestos a su costo de adquisición (2020, pp. 39-40).

En esa línea, existen otros países (tales como Bélgica, Luxemburgo, Noruega, Suiza y España) en los cuales los impuestos al patrimonio recaen sobre bienes o activos, por lo que al encontrarse dentro de su

(18) A ello podríamos sumarle incluso la falta de identificación de un cliente determinado para los servicios prestados, criterio que -entre otras razones- utiliza el Reino Unido para considerar a la actividad de minería fuera del ámbito de aplicación del IVA (OECD, 2020 p. 37). 
definición a las criptomonedas, son considerados como materia imponible. Por citar un caso, tenemos que en Suiza, las criptomonedas en propiedad de personas naturales forman parte de los activos de capital mobiliario, por lo que se encuentran sujetos a impuestos sobre el patrimonio y deberán ser convertidas a francos suizos para cumplir con la obligación tributaria $^{(19)}$ (OECD, 2020, p. 40).

En el caso de España, la Ley 19/1991 establece el Impuesto sobre el Patrimonio, tributo de carácter directo y naturaleza personal que grava el patrimonio neto de las personas físicas, por lo que, en dicho caso, la norma abarcaría también la tenencia de criptomonedas. En efecto, dicha norma señala que el patrimonio neto de la persona física estará constituido por "el conjunto de bienes y derechos de contenido económico de que sea titular, con deducción de las cargas y gravámenes que disminuyan su valor, así como de las deudas y obligaciones personales de las que deba responder", por lo que las criptomonedas serían materia imponible del impuesto al considerarse como bienes de contenido económico.

Sobre el particular, cabe señalar que la determinación del valor de la criptomoneda generaría diversos problemas, pues tal como advierte Gonzales, en virtud del artículo 24 de la Ley 19/1991 aplicable para estos casos, los bienes se valorarían por su precio de mercado en la fecha del devengo del Impuesto, siendo que, en palabras del autor:

(...) existen dos circunstancias relevantes a considerar. En primer lugar, por tratarse de un impuesto cedido, en distintas Comunidades Autónomas existen distintos umbrales para que nazca la obligación de presentar la declaración tributaria. Por otra parte, y dada la extrema volatilidad de estas criptomonedas, bien pudiera suceder que, a la cotización existente a una cierta hora se superarse el umbral y, a otra hora, no. Llevando la situación al extremo pudiera suceder que hiciera sobrepasar el umbral las monedas minadas durante el día o que, dado que pueden cambiarse una[s] criptomonedas por otras intradía con algunas de las combinaciones se superara el umbral y, con otras, no.

Si en algún momento en el futuro se decidiera regular de forma explícita la tributación de las criptomonedas, éstos aspectos deberían regulados para que no sea una cuestión opinable cual es el valor del mercado en la fecha del devengo (2018, p. 40).

Por lo dicho, queda claro que incluso en impuestos sobre el patrimonio, existen dificultades para determinar la liquidación del tributo o incluso para identificar si un sujeto se encuentra dentro del umbral para gravar el patrimonio, lo que implicaría establecer si el patrimonio se encuentre gravado o no.

\section{Tratamiento tributario de las actividades realizadas con criptomonedas en el Perú}

Actualmente, el Perú no cuenta con una legislación especial que regule el tratamiento jurídico de las criptomonedas, por lo que no existe una definición legal sobre las características y naturaleza de dichos bienes, algún ente regulador o supervisor de las transacciones en criptomonedas, ni un mecanismo que permita luchar contra eventuales operaciones ilícitas, entre otros.

En materia tributaria tampoco existe un marco regulatorio específico que abarque el tratamiento tributario que conllevan las operaciones vinculadas a la minería y el intercambio de criptomonedas, siendo los más importantes sus efectos para el Impuesto a la Renta y el Impuesto General a las Ventas (en adelante, "IGV").

En efecto, como bien analiza López, en el Perú la criptomoneda no puede ser considerada como una moneda de curso legal ni como dinero electrónico, de conformidad a lo dispuesto en la Ley 29985 - Ley que regula las características básicas del dinero electrónico como instrumento de inclusión financiera. Tampoco califica como un instrumento de pago en virtud a la Ley 29440 - Ley de los Sistemas de Pagos y de Liquidación de Valores, o como un commoditie, de acuerdo a la Ley 26702 - Ley General del Sistema Financiero y del Sistema de Seguros y Orgánica de la Superintendencia de Banca, Seguros y AFP. Finalmente, no es posible clasificarla como un valor mobiliario según la Ley 27287 - Ley de Títulos Valores; ni como un instrumento financiero o activo financiero de acuerdo a la normativa de la Superintendencia de Banca, Seguros y AFP (2019, pp. 143-145).

(19) Sobre el particular, la administración tributaria suiza ("Swiss Federal Tax Administration") establece un tipo de cambio o de conversión -lo que se ha dado para casos de las criptomonedas de Bitcoin y Ether-; no obstante, se indica que en caso no se cuente con un valor de mercado determinado, se tomará en cuenta el precio de final de año de la plataforma de negociación a través de la cual se ejecutan las operaciones de compra y venta de criptomonedas o, en su defecto, el precio por el que se adquirieron dichas criptomonedas. 
Perspectivas del derecho fiscal comparado: Criptomonedas, transacciones y eventos impositivos. Tratamiento tributario en el Perú, problemas y recomendaciones

A view from comparative tax law: Cryptocurrencies, transactions and taxable events. Tax treatment in Peru, problems and recommendations

Por lo tanto, ante la ausencia normativa específica que verse sobre el tratamiento jurídico de las criptomonedas, se deberá acudir a las normas de carácter general que resulten aplicables. Así, teniendo en cuenta que la criptomoneda es un bien de carácter inmaterial, intangible o incorporal(20), podemos concluir que esta califica como un bien mueble de acuerdo a los artículos 885 y 886 del Código Civil(21). Siendo ello así, el tratamiento tributario de las actividades con criptomonedas en el Perú tendría las siguientes implicancias.

\subsection{Regulación del Impuesto General a las Ventas}

\subsubsection{Actividad de minería}

Para efectos del IGV, cabe preguntarnos si la actividad de minería podría encajarse, desde una primera aproximación, como una prestación de servicios, de conformidad a lo establecido en el inciso b) del artículo 1 de la Ley del IGV. Según el numeral 1 del inciso c) del artículo 3 de la misma Ley, la definición de servicios es la siguiente:

c) Servicios:

1. Toda prestación que una persona realiza para otra y por la cual percibe una retribución o ingreso que se considere renta de tercera categoría para los efectos del Impuesto a la Renta, aun cuando no esté afecto a este último impuesto; incluidos el arrendamiento de bienes muebles e inmuebles y el arrendamiento financiero (...).

Al respecto, somos de la opinión que la propia actividad de minería no tiene una contraparte que otorgue la retribución en criptomonedas al minero que realiza dicha actividad, pues se trata de la adquisición en propiedad de un bien creado o generado por el propio sistema, sin la intervención de un sujeto que entregue dichas criptomonedas a modo de retribución; por lo tanto, no sería posible encajarlo dentro de la definición de servicios, toda vez que no es una actividad que realiza una persona para otra por la cual se percibe una retribución.

Debe advertirse que distinto es el caso en el que un sujeto encarga a otro a realizar la actividad de minería en su nombre para que se transfiera la titularidad de las criptomonedas obtenidas producto de la minería a cambio de una contraprestación (ya sea en dinero, especie o criptomonedas), en cuyo caso nos encontraríamos ante la ejecución de un encargo o mandato de una actividad específica. En dicho supuesto sí podría evidenciarse la ejecución de un servicio entre dos partes plenamente identificadas (sujeto que realiza el encargo y sujeto encargado que realiza la actividad de minería favor del primero) que podría ser materia del IGV en la medida que se considere como una renta de tercera categoría para efectos del Impuesto a la Renta.

Ahora bien, de darse este último caso, consideramos que no podría dejarse fuera del ámbito del IGV la ejecución del servicio de encargo o mandato para obtener criptomonedas en favor de un tercero, en razón a criterios como la poca relación que existe entre la contraprestación en criptomonedas y el esfuerzo realizado por el minero (debido a que no en todos los casos se obtiene un resultado positivo), ya que dichas consideraciones implicarían dificultades para la determinación de la base imponible mas no para la configuración del hecho imponible, en tanto no se encuentran reguladas expresamente en la norma como un supuesto que impida dicha configuración.

\subsubsection{Intercambio de criptomonedas}

Con relación al intercambio de criptomonedas, cabe atender a si las enajenaciones de tales bienes constituyen hechos imponibles para el IGV como venta en el país de bienes muebles según el inciso a) del artículo 1 de la Ley del IGV.

Atendiendo a lo dispuesto en el inciso b) del artículo 3 de la misma Ley, la definición de bienes muebles es la siguiente: "aquellos bienes corporales que pueden llevarse de un lugar a otro, los derechos referentes a los mismos, los signos distintivos, invenciones, derechos de autor, derechos de llave y similares, las naves y aeronaves, así como los documentos y títulos cuya transferencia implique la de cualquiera de los mencionados bienes".

(20) En palabras de Gutiérrez \& Moreno "el bitcoin solo puede calificarse como un bien incorporal que, por ficción legal, recibe el tratamiento genérico previsto por el Código Civil para los bienes muebles porque constituye una realidad nueva cuyas características económicas y funcionales impiden subsumirlo en alguna otra categoría jurídica más específica del ordenamiento peruano". Véase Gutiérrez, O. \& Moreno, A. (2018). El bitcoin: consideraciones financieras y legales sobre su naturaleza y propuesta de enfoque para su regulación. ESAN ediciones (pp. 59-60).

(21) Según el numeral 10 del artículo 886 , son bienes muebles los demás bienes no comprendidos en el artículo 885 . El referido artículo 885 dispone que son bienes inmuebles, entre otros, el suelo, subsuelo, sobresuelo, mar, lagos, ríos, manantiales, corrientes de agua, minas, canteras, depósitos de hidrocarburos, diques, muelles, concesiones, derechos inscribibles en el registro y demás que la ley le confiera tal calidad. 
De lo antes citado podemos concluir que las criptomonedas, al ser bienes muebles intangibles, son de naturaleza distinta a los enlistados en la norma, por lo que su venta no constituiría un hecho imponible para el IGV. Dicho tratamiento resultará aplicable tanto para personas jurídicas como naturales que generen rentas de tercera categoría.

Cabe advertir que, en la práctica, dicho tratamiento resultaría similar a considerar a la criptomoneda como una moneda de curso legal ya que esta última tampoco es considerada como bien mueble para efectos del IGV. Es decir, para efectos del IGV es posible asemejar -al menos gráficamente- el tratamiento de los intercambios de criptomoneda al tratamiento de las operaciones de compra venta de monedas extranjeras realizadas a través de casas de cambio, casos que no se encontrarían gravados con el impuesto.

Por otro lado, consideramos que no resultaría necesario atender a un criterio de pragmatismo para evitar la imposición en materia de IGV (ya sea por razones como la complejidad de establecer un tipo de cambio específico, verificar el cumplimiento de los intercambios de criptomonedas, el anonimato, entre otros), toda vez que dichos intercambios de todas maneras no se encontrarían sujetos al impuesto.

Sin perjuicio de lo dicho, cabe señalar que si bien la venta de criptomonedas no es un hecho gravado con el IGV, las operaciones realizadas en contrapartida a la enajenación de dichos bienes -esto es, las actividades efectuadas como contrapartida a la entrega de la criptomoneda en el intercambio, tales como la enajenación de bienes que constituye una permuta o la prestación de servicios que fue cancelada en especie mediante la entrega de criptomonedas-, desde la perspectiva de los agentes receptores de criptomonedas, podrían generar hechos gravados con el IGV, por lo que el pago de tales operaciones con criptomonedas no deberían suponer consecuencias tributarias diferentes para tales casos. Veamos:

La definición de venta según el numeral 1) del inciso a) del artículo 3 de la Ley del IGV, es "Todo acto por el que se transfieren bienes a título oneroso, independientemente de la designación que se dé a los contratos o negociaciones que originen esa transferencia y de las condiciones pactadas por las partes (...)", por lo que la operación de permuta se encontraría dentro del ámbito de aplicación del impuesto.

Asimismo, como bien indicamos anteriormente, la definición de servicio contempla "Toda prestación que una persona realiza para otra y por la cual percibe una retribución o ingreso que se considere renta de tercera categoría para los efectos del Impuesto a la Renta, aun cuando no esté afecto a este último impuesto (...)", por lo que la retribución en criptomonedas (dación en pago o pago en especie) no impide calificar un servicio como afecto al IGV, pues la entrega de criptomonedas como retribución en especie se considera una renta de tercera categoría, según detallaremos más adelante.

\subsection{Regulación del Impuesto a la Renta}

\subsubsection{Actividad de minería}

Como bien indicamos, la actividad de minería puede llevarse a cabo tanto por personas naturales como por personas jurídicas, y necesariamente se requiere la intervención de los agentes denominados mineros para que realicen las validaciones tecnológicas necesarias para producir y adquirir criptomonedas, para lo cual se requiere principalmente de equipos informáticos funcionales.

Ahora bien, como hemos anotado anteriormente, la minería se centra en realizar la actividad de minado para obtener un beneficio o recompensa -adquisición de criptomonedas-, por lo que no existe una contraparte específica que retribuya la actividad, sino que es producido por el propio sistema. Así, el resultado de la actividad de minería realizada por un minero configuraría un medio de adquisición del derecho de propiedad sobre un bien mueble intangible o inmaterial a favor del minero ${ }^{(22)}$.

Sin perjuicio de lo dicho, debemos mencionar como un punto adicional, que si una empresa o persona jurídica domiciliada en el Perú contrata a los mineros para que estos realicen la actividad de minería en nombre suyo en una relación de dependencia, lo retribuido a dichas personas naturales constituirían una contraprestación a los servicios prestados, ya sea en dinero o en criptomonedas, en cuyo caso sería un pago en especie ${ }^{(23)}$, o una compensación, que calificaría como un servicio

(22) Cabe advertir que, si bien la figura resulta similar a un caso de adquisición de propiedad por apropiación, las disposiciones reguladas en el Código Civil no les resultarían aplicables pues hacen referencia a bienes tangibles o materiales (cosas susceptibles de apropiación).

(23) Véase Borkowski, D. (2020). ¿Cómo se paga el Impuesto a la Renta cuando la renta se paga "en especie”?. Sitio web de PWC Perú. https://desafios.pwc.pe/como-se-paga-el-impuesto-a-la-renta-en-especie/ 
Perspectivas del derecho fiscal comparado: Criptomonedas, transacciones y eventos impositivos. Tratamiento tributario en el Perú, problemas y recomendaciones

A view from comparative tax law: Cryptocurrencies, transactions and taxable events. Tax treatment in Peru, problems and recommendations

gravado con renta de cuarta categoría (López, 2019, p. 146), pues existe una relación inter partes complementaria a la propia actividad de minería.

Al margen de ello, cabe preguntarnos si la adquisición de criptomonedas como bienes podrían calificar como una renta gravada, pues en estricto debemos definir si nos encontramos ante una renta o ingreso gravados con el impuesto, de conformidad a la Ley del Impuesto a la Renta.

En efecto, para considerar que la adquisición de un bien mueble de carácter inmaterial constituye un hecho gravado con el impuesto, debemos atender al concepto de renta gravada establecida en la Ley del Impuesto a la Renta de acuerdo al Capítulo I "Ámbito de aplicación", cuyo artículo 1 establece como hechos gravados, los siguientes:

a) Las rentas que provengan del capital, del trabajo y de la aplicación conjunta de ambos factores, entendiéndose como tales aquellas que provengan de una fuente durable y susceptible de generar ingresos periódicos.

b) Las ganancias de capital.

c) Otros ingresos que provengan de terceros, establecidos por esta Ley.

d) Las rentas imputadas, incluyendo las de goce o disfrute, establecidas por esta Ley.

Como se puede advertir, la Ley del Impuesto a la Renta hace referencia a los términos de renta, ganancia e ingreso, los cuales a nuestro juicio no podrían subsumir el hecho de una adquisición originaria de un bien jurídico, toda vez que el solo hecho de adquirir la propiedad de un bien, ya sea como mercancía o activo de inversión, no constituye una operación que produzca una renta gravable -esto es, un ingreso, ganancia, beneficio, utilidad, entre otros-, por lo que resulta irrelevante identificar si nos encontramos ante una actividad empresarial o no. Veamos:

Como bien esbozamos anteriormente, la actividad de minería deviene en la adquisición de un bien o activo -mercancía o incluso, una inversión- producto del esfuerzo técnico realizado que genera una validación automática del sistema, por lo que carece de una contraparte -tercero- que retribuya dicha labor. En ese sentido, dicha situación imposibilita que se configure alguna relación jurídica contractual -como la permuta, por ejemplo- que tenga como resultado un ingreso o renta bajo los alcances de la norma.

Así, si bien en la norma no existe una referencia expresa respecto a la definición de "ingreso" o "renta", el inciso c) del artículo 1 antes mencionado señala que se encuentran gravados "Otros ingresos que provengan de terceros", lo que nos da a entender que -desde una interpretación sistemática de la norma- para obtener rentas e ingresos gravados se requiere necesariamente la intervención de terceros, esto es, siempre que provengan de cualquier relación jurídica de al menos dos partes.

Asimismo, podemos agregar que -de manera ilustrativa- en este caso nos encontraríamos ante una primera etapa de inversión de una actividad comercial, en la cual se estarían obteniendo recursos (obtención de criptomonedas a través de la minería) para una eventual generación de rentas o ingresos que sí podrían ser eventualmente hechos gravados (tales como la venta o enajenación de las criptomonedas obtenidas por la minería).

Por lo tanto, consideramos que no sería válido sostener que el resultado de la actividad de minería (obtención de la criptomoneda por medios propios del minero) se encuentre sujeta al Impuesto a la Renta como un "ingreso" gravado (en un sentido amplio), ya que en nuestra legislación dicha definición se encuentra enmarcada a rentas e ingresos producidas por operaciones inter partes, mas no para la adquisición de un bien por propia actividad.

En tal sentido, podemos concluir que para el caso peruano sería irrelevante identificar si la actividad de minería es realizada por una persona natural o jurídica, o si, eventualmente, dicha actividad constituye una actividad empresarial o no, pues la obtención de la criptomoneda como bien mueble intangible producto de la minería no implicaría el reconocimiento de una renta gravada per se, ya que no califica como renta, ganancia o ingreso, debido a que no existe una contraparte -o tercero- que haga efectiva dicha renta.

\subsubsection{Intercambio de criptomonedas}

Como bien indicamos, el intercambio de criptomonedas comprende aquellas operaciones de intercambio de la criptomoneda por dinero, bienes -incluyendo las propias criptomonedas-y servicios, en cabeza de los poseedores de las criptomonedas que serán materia de enajenación.

Con relación a este punto, en primer lugar, debemos tener presente que dichas operaciones califican como "enajenación" en los términos del artículo 5 de la Ley del Impuesto a la Renta(24), siendo que el

(24) Artículo 5.- Para los efectos de esta ley, se entiende por enajenación la venta, permuta, cesión definitiva, expropiación, aporte a sociedades y, en general, todo acto de disposición por el que se transmita el dominio a título oneroso. 
intercambio de la criptomoneda por dinero constituye una venta -o compraventa-, el intercambio de la criptomoneda por otros bienes -incluyendo otras criptomonedas- una permuta, y el intercambio de la criptomoneda por servicios un acto de disposición por el que se transmite el dominio a título oneroso.

Teniendo en cuenta ello, de un primer acercamiento, tenemos que la enajenación de una criptomoneda -intercambiopodría estar comprendida en los incisos a) y b) del artículo 1 de la Ley del Impuesto a la Renta como hechos gravados con el impuesto, esto es, como rentas provenientes de la aplicación conjunta del capital y el trabajo -inciso a- o una ganancia de capital -inciso b-.

Ahora bien, desde un punto de vista práctico debemos identificar si la renta obtenida por el intercambio se produce como parte de una actividad empresarial -de tercera categoría- o no, pues se encontrarán gravadas con el Impuesto a la Renta, todas las enajenaciones de criptomonedas producto de una actividad empresarial -de tercera categoríaindependientemente si es efectuada por una persona natural como por una persona jurídica; mientras que no se encontrarán gravadas con el impuesto aquellas efectuadas por personas naturales que no realicen una actividad empresarial, en tanto el resultado de dicha enajenación no constituye una ganancia de capital gravable para tales sujetos, pues implica la enajenación de un bien mueble distinto a los valores mobiliarios señalados en el inciso a) del artículo 2 de la Ley del Impuesto a la Renta ${ }^{(25)}$.

Al respecto, resulta importante advertir que las enajenaciones de criptomonedas no constituyen ganancias de capital gravables para las personas naturales que no realizan actividad empresarial pues solo constituyen rentas gravadas para tales supuestos el caso de venta de inmuebles o valores mobiliarios, concepto que no encaja con la definición de criptomonedas (Lopez, 2019, p. 148).

Dicho esto, debe tenerse en cuenta que si el sujeto que posee las criptomonedas a enajenar es una persona jurídica, es claro que los resultados obtenidos por las enajenaciones de dichos bienes producirán hechos gravados con el impuesto, ya sea que nos encontremos ante (i) una renta proveniente de la aplicación conjunta de capital, criptomonedas adquiridas como mercancía, y trabajo, esto es, una actividad netamente de carácter empresarial, operación que generalmente recaería en los agentes denominados casas de cambio, o (ii) una ganancia de capital obtenida por entidades cuyo giro del negocio no es la venta de criptomonedas, que enajenan criptomonedas que fueron adquiridas como un medio de inversión y que formarían parte de un activo distinto a la mercancía, es decir, por la enajenación de bienes que no están destinados a ser comercializados en el ámbito de un giro de negocio o de empresa(26).

Sin perjuicio de ello, cabe indicar que, de acuerdo al artículo 3 de la Ley del Impuesto a la Renta, en general, constituiría renta gravada de las empresas, cualquier ganancia o ingreso derivado de operaciones con terceros.

Por su parte, si el sujeto que enajena criptomonedas es una persona natural, debe atenderse a si la actividad que realiza proviene de la aplicación conjunta del capital y el trabajo, pues como vimos, la ganancia de capital no resultaría un supuesto gravado en caso de una persona natural.

Así, tenemos que lo importante para poder identificar ello sería verificar la efectiva concurrencia del capital y trabajo en la operación de intercambio -o enajenación de criptomonedas-, lo que a nuestro juicio podría darse en caso de un minero que cuenta con el equipo y los recursos necesarios para obtener criptomonedas -cuya actividad de minería en sí misma implica una búsqueda de carácter informático permanente para conseguir un resultado favorable- $y$, a su vez, realiza diversas actividades de gestión no solo para atender la actividad de minería de una manera eficiente, sino para gestionar la comercialización y venta de las criptomonedas obtenidas, por ejemplo ${ }^{(27)}$.

Por otro lado, cabe señalar que el numeral 3 del artículo 1 de la Ley del Impuesto a la

(25) Artículo 2.- (...)

a) La enajenación, redención o rescate, según sea el caso, de acciones y participaciones representativas del capital, acciones de inversión, certificados, títulos, bonos y papeles comerciales, valores representativos de cédulas hipotecarias, certificados de participación en fondos mutuos de inversión en valores, obligaciones al portador $u$ otros valores al portador y otros valores mobiliarios.

(26) Sobre este último supuesto, debemos precisar que el caso de la enajenación de criptomonedas que generan una ganancia de capital se ampara en lo dispuesto por el artículo 2 de la Ley del Impuesto a la Renta que establece como operaciones que generan ganancias de capital, entre otras: la enajenación de bienes adquiridos en pago de operaciones habituales o para cancelar créditos provenientes de las mismas y la enajenación de bienes de cualquier naturaleza que constituyan activos de personas jurídicas.

(27) A título ilustrativo, con relación a actividades realizadas en la web, podemos mencionar un criterio emitido por el Tribunal Fiscal en la Resolución 09934-5-2017, en el cual se concluyó que los ingresos producidos de las actividades realizadas por una persona 
Perspectivas del derecho fiscal comparado: Criptomonedas, transacciones y eventos impositivos. Tratamiento tributario en el Perú, problemas y recomendaciones

A view from comparative tax law: Cryptocurrencies, transactions and taxable events. Tax treatment in Peru, problems and recommendations

Renta establece que están incluidas dentro de este tipo de rentas "los resultados de la venta, cambio o disposición habitual de bienes", con lo cual podríamos pensar en algún supuesto distinto para la configuración de una renta empresarial; sin embargo, como bien indica López, la norma no establece algún "criterio de habitualidad objetivo -basado en un número de ventas en un periodo, por ejemplo- aplicable para el caso de la compra y venta de Bitcoins por personas naturales", y agrega que "podría ser discutible que una persona natural que adquiere Bitcoins solo para su enajenación -especulación- pueda ser de plano descartada como alguien que realiza una actividad habitual; y por tanto, empresarial” (2019, p. 149).

Lo expuesto en el párrafo anterior se encontraría alineado a lo dispuesto en el inciso a) del artículo 28 de la Ley del Impuesto a la Renta, en el sentido que califican como rentas de tercera categoría las derivadas, en general, "de cualquier otra actividad que constituya negocio habitual de compra o producción y venta, permuta o disposición de bienes".

En atención a lo comentado, consideramos que para efectos de determinar si la actividad constituye una renta empresarial, no sería aplicable el criterio de la obtención de ganancias en base a la especulación o identificar el ánimo de lucro del poseedor de criptomonedas, dado que en la legislación no se ha contemplado de manera expresa dicho supuesto para la enajenación de bienes muebles intangibles como es el caso de las criptomonedas; tal como sí se tiene en un caso similar respecto a la enajenación de inmuebles adquiridos para la enajenación, por ejemplo.

Dejando dicha salvedad de lado, hay que tener presente que en caso nos encontremos ante un supuesto de una renta empresarial producida por la enajenación de criptomonedas según lo antes expuesto, una cuestión particular resulta determinar la renta bruta, pues cuando los ingresos provienen de la enajenación de bienes, el artículo 20 de la Ley del Impuesto a la Renta establece diversas reglas en torno al costo computable de los bienes enajenados, pudiendo ser aquel el costo de adquisición, producción o construcción o, en su caso, el valor de ingreso al patrimonio o valor en el último inventario determinado conforme a ley.
Al respecto, cabe anotar algunas observaciones. Si bien el costo de producción o construcción resultaría aplicable en la medida que las criptomonedas sean obtenidas por la actividad de minería, y el costo de adquisición en la medida que dichos bienes se obtengan a través del intercambio (específicamente por la adquisición de criptomonedas a cambio de dinero o servicios); el numeral 21.5 del artículo 21 de la Ley del Impuesto a la Renta contempla una regla especial para determinar el costo computable de los intangibles adquiridos de terceros, pues señala: "El costo computable será el costo de adquisición disminuido en las amortizaciones que correspondan de acuerdo a Ley". Creemos que dicha norma generaría dificultades en la aplicación de las reglas del costo computable, pues a pesar de que la criptomoneda calificaría como un bien intangible, su amortización no es admitida para efectos del Impuesto a la Renta, de acuerdo con el artículo 44 de la Ley del Impuesto a la Renta(28).

Asimismo, existe una regla especial para el supuesto de adquisición de un bien por permuta regulada en el numeral 21.7 del artículo 21 de la Ley del Impuesto a la Renta que establece: "el costo computable de los bienes recibidos en una permuta será el valor de mercado de dichos bienes". Dicha norma resultaría aplicable en para el caso de adquisiciones de criptomonedas mediante permutas (a cambio de bienes, como lo sería también otra criptomoneda), siendo la situación de la determinación del valor de mercado de los bienes un tema de gran complejidad para la determinación de la renta bruta, en tanto los ingresos provenientes de las transacciones de permuta también se ajustan a valor de mercado ${ }^{(29)}$.

natural en su página web con el objetivo de crear contenido y obtener ingresos en función a la interacción que se obtenga con la publicidad colocada en dichas páginas web se configuraba como una renta proveniente del capital y trabajo, esto es, una renta de tercera categoría en la figura de "servicios comerciales" (inciso a del artículo 28 de la Ley del Impuesto a la Renta), pues el órgano colegiado advirtió en dicha actividad una intervención permanente para lograr el mantenimiento, funcionamiento y actualización de contenido y la implementación de requerimientos específicos, lo que evidenciaba una estructura y organización de trabajo, dirigidos a lograr mantener o incrementar el número de clics que le permitan mantener la fuente generadora de renta.

(28) Según el inciso g) del artículo 44 de la Ley del Impuesto a la Renta y el inciso a) del artículo 25 de su Reglamento, el precio pagado por los activos intangibles podrá deducirse como gasto o amortizarse proporcionalmente siempre que sean de duración limitada, siendo estos aquellos cuya vida útil este limitada por la ley o por su propia naturaleza, tales como las patentes, los modelos de utilidad, los derechos de autor, los derechos de llave, los diseños o modelos, planos, procesos o fórmulas secretas, y los programas de instrucciones para computadoras (Software), con excepción de las marcas de fábrica y el fondo de comercio (Goodwill) (Sunat, 2009).

(29) Véase Medrano, H. (2011). Impuesto a la Renta y determinación del costo computable. Revista IUS ET VERITAS, 42, 320-327. https://revistas.pucp.edu.pe/index.php/iusetveritas/article/view/12096 
Por último, cabe señalar que la contraparte en la relación jurídica proveniente de la enajenación de criptomonedas, que podría ser aquel sujeto que intercambia dicha adquisición de criptomonedas por dinero, otro bien o un servicio, no altera las implicancias tributarias que conllevan las operaciones de venta del bien y prestación de servicios -en cuyo caso, el tratamiento tributario recae en cabeza de los agentes receptores de criptomonedas-. Así, la prestación de un servicio a cambio de criptomonedas implicaría el reconocimiento de un ingreso gravado como pago en especie ${ }^{(30)}$-o dación en pago-; y la enajenación de un bien -incluso otra criptomoneda- por la adquisición de criptomonedas generaría una permuta, a la que le resultarían aplicable las reglas antes expuestas ${ }^{(31)}$.

\section{Situación actual de la normativa tributaria peruana aplicable a transacciones con criptomonedas desde una perspectiva comparada: Problemas identificados y posibles aspectos a tener en cuenta para una futura regulación}

\subsection{Impuesto General a las Ventas: Problemas pragmáticos resueltos}

Teniendo en cuenta la legislación comparada, podemos decir que el tratamiento de las actividades de minería e intercambio de criptomonedas de criptomonedas en materia del IGV resulta acorde con los lineamientos establecidos en materia del IVA en el sentido que no implican hechos gravados y no suponen una interferencia con la imposición que recae en las operaciones efectuadas en contrapartida -contraprestación en entrega de bienes o prestación de servicios-.

Cabe resaltar que si bien las razones son de distinta índole -ya que los problemas advertidos en otras legislaciones radican en la complejidad del tratamiento tributario de las permutas o intercambios -determinación del valor, trazabilidad de los intangibles, entre otros-, por lo que se consideran a las enajenaciones de criptomonedas como un medio de pago-, la legislación peruana en materia de IGV no requeriría mayores ajustes, en tanto en la práctica también se estaría reconociendo una semejanza -al menos en algún sentido- entre las criptomonedas y las monedas de curso legal -o dinero- para efectos de este impuesto.

Asimismo, no creemos que resulte pertinente hacer uso de la herramienta legislativa de considerar a las criptomonedas como una moneda de curso legal, pues si bien podría simplificar el tratamiento tributario como para el IGV, las implicancias de tal regulación aun es desconocida, siendo las más evidentes la utilización de algunas reglas específicas en materia del Impuesto a la Renta.

\subsection{Impuesto a la Renta: ¿Forzar} interpretaciones o realizar ajustes normativos?

En materia del Impuesto a la Renta, sí cabe atender a diversas circunstancias que podrían generar situaciones no claras que, en el mercado de criptomonedas, implicarían una vulneración a los principios tributarios y también a supuestos de evasión o elusión de impuestos, así como la reducción dolosa de las bases imponibles.

Respecto a la actividad de minería y obtención originaria de criptomonedas cabe preguntarnos ¿ello podría constituir -en el futuro- una "renta" gravada con el Impuesto a la Renta en virtud a las teorías de Flujo de Riqueza o de Consumo más Incremento Patrimonial? Qué duda cabe que dicha adquisición constituye un aumento significativo del patrimonio del sujeto que lo adquiere por lo que podría incorporarse dentro de la definición de "ingreso" o "renta" de manera expresa y así evitar alguna discusión respecto a si resulta necesaria la intervención de un tercero para considerar una renta gravada para efectos del Impuesto a la Renta.

Cabe señalar que, si bien esta propuesta tendría como primer sustento la capacidad contributiva de los sujetos, debemos advertir que podría entrar en colusión la manifestación de riqueza involucrada, pues dicha imposición podría asemejarse a un gravamen sobre el patrimonio y no sobre la renta.

Al respecto, González advierte que "la posesión de criptomonedas, aunque no sean dinero, sí que son manifestación de una riqueza, aunque sea potencial", por lo que

(30) De acuerdo al artículo 3 de la Ley del Impuesto a la Renta "Los ingresos provenientes de terceros que se encuentran gravados por esta ley, cualquiera sea su denominación, especie o forma de pago (...)".

(31) En los casos de permuta de bienes se entiende que existen dos enajenaciones gravadas con el Impuesto a la Renta en cabeza de cada una de las partes intervinientes. 
Perspectivas del derecho fiscal comparado: Criptomonedas, transacciones y eventos impositivos. Tratamiento tributario en el Perú, problemas y recomendaciones

A view from comparative tax law: Cryptocurrencies, transactions and taxable events. Tax treatment in Peru, problems and recommendations

recomienda que desde la perspectiva de la imposición sobre el patrimonio "dadas las enormes fluctuaciones del valor de las monedas incluso en un solo día, podría ser oportuna una mayor precisión sobre la cotización que debe ser utilizada por el declarante, por ejemplo, la de cierre del último día del año o la máxima o la de apertura" (2018, p. 49).

En la misma línea, Rangel anota lo siguiente: en atención a los principios del deber de contribuir, capacidad económica y capacidad contributiva "la utilización de criptomonedas puede constituir manifestaciones de capacidad económica, es decir, si los operadores realizan actividades que configuran una obligación tributaria, teniendo capacidad económica para ello, deben contribuir con las cargas públicas" (2019, p. 73). Efectivamente, entendemos que, si un sujeto puede realizar diversas y mayor cantidad de operaciones a su favor producto del incremento de su patrimonio por la adquisición y tenencia de criptomonedas, qué duda cabe que existe una manifestación de riqueza en tanto ello evidencia una mayor posibilidad de consumo, por ejemplo. De esta manera, plantea el autor que "el incremento de patrimonio de los actores que participan en las criptonegociaciones, puede ser sometido al impuesto sobre sociedades, impuesto sobre la renta de personas físicas o al impuesto sobre patrimonios, según la configuración de los diversos sistemas tributarios" (Rangel, 2019, p. 75).

Otro tema relevante es evaluar la posibilidad de crear reglas específicas para considerar a las personas naturales como generadores de rentas empresariales por la enajenación de criptomonedas -tales como reglas de habitualidad o supuestos específicos de aplicación conjunta de capital y trabajo-.

Por otro lado, también podría considerarse la ampliación del concepto ganancia de capital gravada para las personas naturales que no realizan actividad empresarial, en la que se abarque también a las producidas por la enajenación de criptomonedas, en tanto es evidente el enorme beneficio económico que se podría conseguir.

Un paso en esta línea se observa en Argentina, pues en el año 2017, mediante la Ley 27430, se modificó la Ley de Impuesto a las Ganancias incorporando como hecho gravado los resultados de la enajenación proveniente de monedas digitales, en clara alusión a las criptomonedas. La referida norma establece lo siguiente:

Artículo 2. A los efectos de esta ley son ganancias, sin perjuicio de lo dispuesto especialmente en cada categoría y aun cuando no se indiquen en ellas:

4) los resultados derivados de la enajenación de acciones, valores representativos y certificados de depósito de acciones y demás valores, cuotas y participaciones sociales -incluidas cuotapartes de fondos comunes de inversión y certificados de participación de fideicomisos financieros y cualquier otro derecho sobre fideicomisos y contratos similares-, monedas digitales, títulos, bonos y demás valores, cualquiera sea el sujeto que las obtenga.
Sobre dicha norma, Zocaro apunta lo siguiente: "Respecto de la definición legal del concepto moneda digital, ni la LIG ni su decreto reglamentario ni ninguna norma posterior arrojó luz sobre el asunto; ni la doctrina posee una opinión unívoca". Advierte que incluso algunos tributaristas son de la opinión que, al no existir una definición sobre "moneda digital", que constituye un elemento esencial del hecho imponible, el impuesto que recae sobre la venta de estos activos devendría en inconstitucional, al no respetarse el principio de reserva de ley (2020, p. 31). Por su parte, Laise \& Manzo-Ugas evalúan, desde su perspectiva, la decisión legislativa de gravar las rentas provenientes de la enajenación de monedas virtuales o digitales en argentina realizando un test o "análisis de razonabilidad" -que implica realizar subjuicios de idoneidad, necesidad y razonabilidad en sentido estricto-, en el cual se pondera si la medida dictada garante de la recaudación fiscal respeta los derechos de libertad y propiedad (2019, p. 115).

Para los autores, la medida resulta idónea pues el gravamen contribuye con la finalidad recaudatoria que persigue la norma, es necesaria en tanto no se evidencia algún medio alternativo que logre el mismo objetivo -garantizar la recaudación de las transacciones que tienen un alto grado de anonimato-; y, respeta el criterio de razonabilidad en sentido estricto, ya que si bien existe una afectación al derecho de propiedad y la libertad, este no es de tal magnitud que imposibilita su ejercicio, es decir, no afecta su contenido esencial, siendo que el tributo no es de carácter confiscatorio (Laise \& Manzo-Ugas, 2019, pp. 116-121).

Este análisis resulta interesante en la medida que se pondera el derecho de propiedad y de libertad de los sujetos contra un valor legítimo del Estado que consiste en garantizar la recaudación ante supuestos que implican una probabilidad de elusión o evasión de impuestos. A nuestro entender, dicha evaluación recae en un mecanismo de defensa constitucional para verificar si, en el ejercicio de la potestad estatal para establecer tributos, se respeta la capacidad contributiva y el principio de no confiscatoriedad, como finalmente advierten los autores. 
Además, somos de la opinión que el examen podría complementarse si se añadiera como elemento a la ponderación los fines extrafiscales del tributo cuyo uno de sus objetivos es la lucha contra la evasión. Así, la medida se justificaría constitucionalmente no solo en atención a una manifestación de capacidad contributiva sino también en los fines extrafiscales del tributo como la lucha contra la evasión, que se sustentan en el deber de contribuir y el principio de Igualdad Tributaria(32).

En tal sentido, sostenemos que ante una eventual regulación en ejercicio de la potestad tributaria del Estado en los términos comentados, el derecho de propiedad, el respecto a la capacidad contributiva y el principio de no confiscatoriedad podrían ser ponderados contra los principios de Igualdad Tributaria y el deber de contribuir, toda vez que la regulación respondería a la manifestación de riqueza de los sujetos que adquieren criptomonedas y también a lucha contra la evasión debido al alto grado de anonimato de los usuarios, en comparación de los bienes gravados con el impuesto como ganancia de capital -tales como los valores mobiliarios, por ejemplo- e incluso el uso del dinero o monedas de curso legal.

Un punto adicional que también debe tenerse en la mira es el uso de la herramienta contable para efectos tributarios, ya sea adoptándolas como normas jurídicas específicas o haciendo remisión a ellas, en aplicación supletoria a las normas tributarias, con lo cual se reabriría nuevamente la discusión de si resultase pertinente y oportuno incorporar algunos aspectos contables para afinar el tratamiento tributario de las criptomonedas, especialmente en el Impuesto a la Renta. Entre los temas a considerar tendríamos la definición de activo intangible, el registro de los costos asociados y fluctuaciones de valor, criterio de devengado para el reconocimiento de ingresos y gastos, entre otros.

Por último, cabe señalar que también deben darse reglas claras respecto al sustento documentario que permita acreditar los costos incurridos en la obtención de criptomonedas, pues la normativa sobre la emisión de comprobantes de pago podría quedar desfasada ante las características particulares de las criptomonedas. Ello también permitiría otorgar a los contribuyentes un mecanismo para sustentar los ingresos y gastos incurridos, para evitar alguna la detección e imputación de algún supuesto de incremento patrimonial no justificado realizado por la Administración Tributaria.

Sin perjuicio de ello, no estaría de más guardar toda la información posible que permita justificar las adquisiciones de criptomonedas, tales como correos electrónicos, datos criptográficos de los monederos virtuales y transferencias bancarias con las casas de custodia y cambio, entre otros.

\subsection{Cuestiones transversales que afectan el sistema tributario: Lucha contra la evasión y el incumplimiento tributario} Un tema transversal que perjudica al sistema tributario peruano consiste en la falta de control y supervisión de las transacciones realizadas con criptomonedas, siendo las cuestionas más importantes a resolver en materia fiscal, la trazabilidad de las operaciones y los agentes que realizan actividades en criptomonedas; y, la determinación del valor de las criptomonedas.

En efecto, en tanto existe un alto grado de anonimato en las actividades con criptomonedas, consideramos que el riesgo de perder recaudación aumenta y en consecuencia se incrementarían situaciones de evasión de impuestos, ya sea como resultado ante la falta de información de las entidades tributarias, la complejidad de las transacciones, e incluso la dificultad que implica establecer un valor razonable de las criptomonedas.

Cabe señalar que las situaciones de elusión y evasión de impuestos podrían verse muy comprometida. A título ilustrativo podemos citar el siguiente caso: En el Perú existen diversos mecanismos que luchan contra la evasión, como la Ley 28194 - Ley para la Lucha contra la Evasión y para la Formalización de la Economía, que establece que las obligaciones que se cumplan mediante el pago de determinadas sumas de dinero(33) se deberán pagar utilizando Medios de Pago a través del sistema financiero, tales como los depósitos en cuentas, giros, transferencias de fondos, órdenes de pago, tarjetas de débito expedidas en el país, tarjetas de crédito expedidas, cheques, remesas, cartas de crédito u otros.

El artículo 8 de la norma establece lo siguiente:

(32) Véase AELE. (2007). La evasión como clave de lectura del fenómeno tributario. Revista Análisis Tributario, 236, 16-19.

(33) El monto a partir del cual se deberá utilizar Medios de Pago es de tres mil quinientos nuevos soles (S/. 3,500) o mil dólares americanos (US\$1,000). 
Perspectivas del derecho fiscal comparado: Criptomonedas, transacciones y eventos impositivos. Tratamiento tributario en el Perú, problemas y recomendaciones

A view from comparative tax law: Cryptocurrencies, transactions and taxable events. Tax treatment in Peru, problems and recommendations

Para efectos tributarios, los pagos que se efectúen sin utilizar Medios de Pago no darán derecho a deducir gastos, costos o créditos; a efectuar compensaciones ni a solicitar devoluciones de tributos, saldos a favor, reintegros tributarios, recuperación anticipada, restitución de derechos arancelarios.

A su vez, dicha norma regula el impuesto a las transacciones financieras que grava determinadas operaciones realizadas a través de las empresas del sistema financiero, así como aquellas realizadas en cualquier otra entidad creada para realizar intermediación financiera.

Ahora bien, si nos encontramos ante un sujeto que reemplace el uso de las monedas de curso legal por las criptomonedas, cabría preguntarnos: ¿Ello tiene como consecuencia la inaplicación voluntaria de la norma? ¿Sería posible y justo validar para efectos tributarios una transacción sin uso de medios al no resultarle aplicable lo dispuesto en la norma? ¿Constituiría un acto de elusión del impuesto a las transacciones financieras?

Dicho esto, y dado que los alcances de las criptomonedas en el mercado económico del Perú se extienden cada vez más, resulta necesario tomar medidas para fortalecer la lucha contra la evasión y el incumplimiento tributario y, a su vez, evitar que se perjudique la recaudación fiscal por situaciones no claras vinculadas con actividades relativas al mercado de criptomonedas.

Debemos resaltar que lo dicho no es un tema menor, pues la autonomía y falta de control sobre las criptomonedas facilitan que las rentas o ingresos no reconocidos o declarados sean difíciles de fiscalizar y cobrar, esto es, para que se obtengan un cumplimiento forzado de las obligaciones tributarias. Así, por ejemplo, algunos autores afirman que el mercado de criptomonedas sería una versión perfeccionada de un paraíso fiscal(34).

\section{En palabras de Rangel:}

(...) las operaciones realizadas con criptomonedas que configuran hechos imponibles generan consecuencias jurídicas traducidas como obligaciones tributarias que no deben, en principio, ser evadidas por los actores del criptomundo; no obstante, estas operaciones se constituyen mediante mecanismos virtuales donde posiblemente los actores no interactúan personalmente entre sí, por ello se vuelve una tarea titánica la que debe realizar el Estado para identificarlos a plenitud, siendo los potenciales sujetos pasivos que intervienen en el mundo virtual evasores por acción u omisión; ejemplo de ello es la tributación en el entorno virtual que trae consigo otros problemas que escapan a la presente obra, tal como sucede por ejemplo, con la deslocalización de las operaciones económicas realizadas en internet” (2019, pp. 75-76).
En atención a ello, para contrarrestar los efectos adversos anotados, podemos citar algunos casos en los que ya se han adoptado medidas colaborativas que permitirían aliviar las situaciones de peligro fiscal en el uso de criptomonedas. A modo de recomendación tenemos lo siguiente.

Por un lado, Begoña señala que una posible vía de actuación para lograr suministrar información con trascendencia tributaria sobre el uso de Bitcoin a la administración tributaria "es ampliar el concepto de intermediario financiero, incluyendo dentro de éste a sujetos que tradicionalmente ha sido excluidos de esta categoría, como sería el caso de los exchangers o casas de cambio, intermediarios naturales del sistema Bitcoin" (2018, p. 155), pues dichos agentes requieren de forma preventiva cierto tipo de identificación de sus usuarios: facturas con nombre y dirección, documentos de identidad como pasaporte o carnet de conducir u otros. Asimismo, anota que ello podría recaer también sobre los establecimientos comerciales que aceptan el pago de sus productos o servicios (Begoña, 2018, p. 155).

Por otro lado, puede verse las medidas adoptadas en Brasil, pues la resolución identificada con el Numeral 1.888/2019 impuso a las casas de cambio de criptomonedas en territorio brasileño la presentación de un reporte mensual de todas sus operaciones con criptoactivos, sin límite de valor. En tal sentido, Rangel apunta que las personas naturales y jurídicas residentes en Brasil, se encuentran obligadas a informar a la administración tributaria aquellas operaciones con criptomonedas realizadas en casas de cambio domiciliadas en el extranjero (Rangel, 2019, p. 79).

De igual modo, países como Argentina, Australia y Reino Unido, ya han establecidos ciertas reglas para suministrar información mediante la presentación de declaraciones a las autoridades fiscales. Así, por ejemplo, en Argentina se cuenta con la Resolución General $4614 / 2019^{(35)}$, que impone la obligación

(34) Véase Marian, O. (2013). Are Cryptocurrencies Super Tax Havens. Michigan Law Review First Impressions, 112, 38-48. https:// scholarship.law.ufl.edu/cgi/viewcontent.cgi?referer=\&httpsredir=1\&article=1365\&context=facultypub

(35) Véase la Resolución 4614/2019 emitida por la Administración Federal de Ingresos Públicos en el portal web “InfoLEG” del Ministerio de Justicia y Derechos Humanos de la República de Argentina, que brinda información legislativa. http://servicios.infoleg.gob.ar/ infolegInternet/anexos/330000-334999/330689/texact.htm 
de suministrar información a los agentes denominados "Agrupadores o Agregadores de Medios de Pago" -por ejemplo las plataformas de las empresas de tecnología en medios de pago tales como "TodoPago" o "MercadoPago"-(36) y para las casas de cambio, intermediadoras o "exchanges", tales como Bitex.la, Ualá u otros ${ }^{(37)}$. Estos últimos, son referidos por el artículo 3 de la referida norma como aquellos "sujetos que administran, gestionan, controlan o procesan movimientos de activos a través de plataformas de gestión electrónicas o digitales, por cuenta y orden de personas humanas y jurídicas residentes en el país o en el exterior", quienes deben suministrar información relativa a los datos sobre las cuentas, sus movimientos -montos, tipo de ingreso- tales como efectivo, en moneda extranjera o en criptomonedas -saldos- y los individuos involucrados en las cuentas -nombres, razón social, número de contribuyente-.

Por último, recientemente en España se publicó la Ley $11 / 2021$ que dicta medidas de prevención y lucha contra el fraude fiscal en la cual se establecen normas contra las prácticas de elusión fiscal que inciden directamente en el funcionamiento del mercado interior, de modificación de diversas normas tributarias y en materia de regulación del juego. Esta norma pretende reforzar el control tributario sobre los hechos imponibles relativos a monedas virtuales -criptomonedas-, estableciendo nuevas obligaciones de información sobre la tenencia y operaciones con dichas criptomonedas (BOE, 2021).

En efecto, dicha norma introduce una obligación de suministro de información sobre los saldos que mantienen los titulares de monedas virtuales, a cargo de quienes proporcionen servicios en nombre de otras personas o entidades para salvaguardar claves criptográficas privadas que posibilitan la tenencia y utilización de tales monedas, incluidos los proveedores o las proveedoras de servicios de cambio de las citadas monedas si también prestan el mencionado servicio de tenencia. Asimismo, para estas mismas personas o entidades, se establece la obligación de suministrar información acerca de las operaciones sobre monedas virtuales -adquisición, transmisión, permuta, transferencia, cobros y pagos- en las que intervengan. Esta obligación se extiende inclusive a quienes realicen ofertas iniciales de nuevas monedas virtuales -o ICOs- (BOE, 2021).

Como puede notar el lector, nos encontramos ante una corriente regulatoria según la cual se afronta el problema del alto grado de anonimato de los sujetos intervinientes en actividades con criptomonedas que podrían generar un riesgo en la recaudación, supuestos de evasión e incumplimiento tributario. Por lo tanto, el Perú requiere adoptar medidas necesarias para evitar los problemas derivados de dichas actividades y seguir en pie de lucha contra la evasión fiscal, siempre respetando los principios del derecho tributario y los derechos del contribuyente.

\section{Conclusiones}

Debido al incremento en el uso de criptomonedas en el mercado peruano y sus características particularidades -bienes intangibles que permiten un alto grado de anonimato en las transacciones, cuyo valor es muy volátil y que no cuentan con el respaldo de alguna entidad, que pueda controlarlas y/o supervisarlas-, resulta necesario realizar una evaluación integral del sistema tributario actual teniendo como directriz los parámetros desarrollados en la legislación comparada que se encuentran en los pronunciamientos de las autoridades administrativas, las recientes modificaciones legislativas y las diversas opiniones de los juristas en la materia.

En resumen, en materia del IGV, consideramos que las actividades de minería realizadas por los propios agentes para la obtención de criptomonedas, así como las operaciones de intercambio de estas, no constituyen hechos gravados con el impuesto debido a que no calzan con los conceptos de "servicio" ni "bienes muebles" respectivamente, según lo dispuesto en la normativa del IGV. Así, dicho tratamiento resultaría semejante al desarrollado en la mayor parte de legislaciones analizadas en materia del impuesto al consumo o valor agregado, en las cuales dichas operaciones no se encuentran sujetas a dicho impuesto principalmente por razones pragmáticas.

Con relación al Impuesto a la Renta, por un lado, tenemos que los resultados de la actividad de minería (obtención de

(36) En estos casos, la información a suministrar es respecto a los vendedores, locadores o prestadores de servicios adheridos al sistema de gestión de pago electrónico, los montos de las operaciones realizadas y el importe de la comisión cobrada por dicho servicio.

(37) Véase Castillejo, V. (2019). Régimen informativo para los exchanges de criptomonedas (RG AFIP 4614/2019). Abogados.com.ar https://abogados.com.ar/regimen-informativo-para-los-exchanges-de-criptomonedas-rg-afip-46142019/24643 
Perspectivas del derecho fiscal comparado: Criptomonedas, transacciones y eventos impositivos. Tratamiento tributario en el Perú, problemas y recomendaciones

A view from comparative tax law: Cryptocurrencies, transactions and taxable events. Tax treatment in Peru, problems and recommendations

criptomonedas producidas o generadas por el minero) no calificarían como supuestos gravados con el impuesto en tanto no existe una relación con un tercero (una contraparte) que permita considerar a dichas adquisiciones dentro de la definición de ingresos o rentas gravadas según la normativa. Por otro lado, señalamos que las operaciones de intercambio de criptomonedas sí generan hechos gravados con el impuesto en tanto se evidencie una actividad empresarial, siendo un tema de particular atención las operaciones realizadas por personas naturales en función a los criterios habitualidad en sus transacciones o de la aplicación conjunta del capital y trabajo que pueda evidenciar la actividad empresarial.

Desde ese enfoque, somos de la opinión que la normativa tributaria vigente aún tiene espacios por mejorar, pues al no tener una regulación especial en la materia ni un pronunciamiento oficial por parte de la Administración Tributaria, el tratamiento impositivo de las actividades con criptomonedas -actividades de minado e intercambios- resulta poco claro, lo que deja un espacio abierto para el incumplimiento tributario, la reducción de la base imponible, y la evasión o la elusión fiscal, principalmente en materia del Impuesto a la Renta.

Por ello, en atención a los criterios expuestos de acuerdo a la normativa extranjera, se han propuesto algunas medidas para una eventual regulación, tanto en materia del Impuesto la Renta -tales como la incorporación de supuestos o hechos gravados, la creación de reglas para la determinación de rentas empresariales, la inclusión de conceptos claves en la legislación, entre otros- como también respecto a determinadas obligaciones formales relativas al suministro de información, que podrían adoptarse atendiendo a los principios tributarios como la capacidad contributiva y el deber de contribuir; y, de esta manera, evitar perjuicios en la recaudación fiscal y poder mejorar el sistema tributario.

En consecuencia, declaramos que es hora de sumarnos a la corriente regulatoria sobre las transacciones con criptomonedas.

\section{Referencias bibliográficas}

Allende, M. (2018). Blockchain: Cómo desarrollar confianza en entornos complejos para generar valor de impacto social. Banco Interamericano de Desarrollo. https://publications.iadb.org/es/blockchain-comodesarrollar-confianza-en-entornos-complejos-para-generar-valorde-impacto-social.

Begoña, B. (2018). La Administración Tributaria frente al anonimato de las criptomonedas: La seudonimia del Bitcoin. VI Encuentro de Derecho Financiero y Tributario: Tendencias y retos del Derecho Financiero y Tributario (1era parte), Instituto de Estudios Fiscales, 10, 149-161. https://www.ief.es/docs/destacados/publicaciones/ documentos_trabajo/2018_10.pdf

García-Torres, M. (2018). Problemas en la tributación de las operaciones con Bitcoins: calificación, prueba, valoración y control de las rentas generadas. VI Encuentro de Derecho Financiero y Tributario: Tendencias y retos del Derecho Financiero y Tributario (1era parte), Instituto de Estudios Fiscales, 10, 86-98. https:// www.ief.es/docs/destacados/publicaciones/ documentos_trabajo/2018_10.pdf

Gómez Rodríguez, C. (2016). Bitcoin: problemas reales. En E. Téllez, Derecho y TIC. Vertientes actuales, 265-297. Universidad Nacional Autónoma de México. http://ru.juridicas.unam.mx/xmlui/ handle/123456789/36367

González de Frutos, U. (2018). La fiscalidad en el mundo Blockchain. Estudios financieros. Revista de contabilidad y tributación. Comentarios, casos prácticos, 425, 5-36. https://udimundus.udima.es/ bitstream/handle/20.500.12226/302/fiscalidad. pdf? sequence $=1 \&$ isAllowed $=y$

González García, I. (2018). Control tributario de las criptomonedas. VI Encuentro de Derecho Financiero y Tributario: Tendencias y retos del Derecho Financiero y Tributario (1era parte), Instituto de Estudios Fiscales, 10, 36-49. https:// www.ief.es/docs/destacados/publicaciones/ documentos_trabajo/2018_10.pdf

Grupo de Acción Financiera Internacional. (2015). Directrices para un enfoque basado en riesgo monedas virtuales. https://www.fatf-gafi.org/media/ fatf/documents/Directrices-para-enfoque-basadaen-riesgo-Monedas-virtuales.pdf

Laise, L. \& Manzo-Ugas, G. (2019). Bases para la interpretación y regulación razonable de las criptomonedas: naturaleza, dificultades y desafíos constitucionales. Cuadernos del CENDES, 36(100), 107-124. http://saber.ucv.ve/ojs/index.php/ rev_cc/article/view/16731

López, L. (2019). Bitcoin: ¿Tenerla o ignorarla? Una aproximación hacia el tratamiento tributario peruano de la criptomoneda más famosa del mundo. Revista IUS ET VERITAS, 58, 140-153. https://revistas.pucp.edu.pe/index.php/iusetveritas/ article/view/21278

Organisation for Economic Co-operation and Development. (2020). Taxing Virtual Currencies: An Overview of Tax Treatments and Emerging Tax Policy Issues. Paris. https://www.oecd.org/tax/ tax-policy/taxing-virtual-currencies-an-overviewof-tax-treatments-and-emerging-tax-policy-issues. htm

Pérez-Carasa, I. (2018). Tratamiento tributario del Bitcoin y demás criptomonedas. Cuadernos de Derecho y Comercio, 70, 131-180.

Ramírez, V. (2018). Hacia un tratamiento uniforme del bitcoin desde una perspectiva fiscal global [tesis para el Máster en Fiscalidad Internacional, Universidad Internacional de La Rioja, Sevilla]. 
Repositorio Digital Re-Unir. https://reunir.unir.net/ handle/123456789/6587

Rangel, L. (2019). Aproximaciones jurídicas al marco regulatorio de las criptomonedas. Caracas. https://dialnet.unirioja.es/servlet/ libro?codigo $=767381$

Varela, R. (2006). Criptografía, una necesidad moderna. Revista Digital Universitaria - UNAM,
7(7). http://www.revista.unam.mx/vol.7/num7/art56/jul_art56.pdf Zambrano, J., Yepes, S., Osorio, S., López, M., Rodríguez, C., Carazo, D. \& López, J. (2019). Aspectos tributarios de las transacciones en criptomonedas: el caso de los Bitcoins. Revista Instituto Colombiano de Derecho Tributario, 80, 43-69.

Zocaro, M. (2020). El confuso marco tributario de las criptomonedas. Criptomonedas en Argentina: Una mirada integral de la nueva moneda digital. Suplemento Especial Errepar, 19-29. (19) 


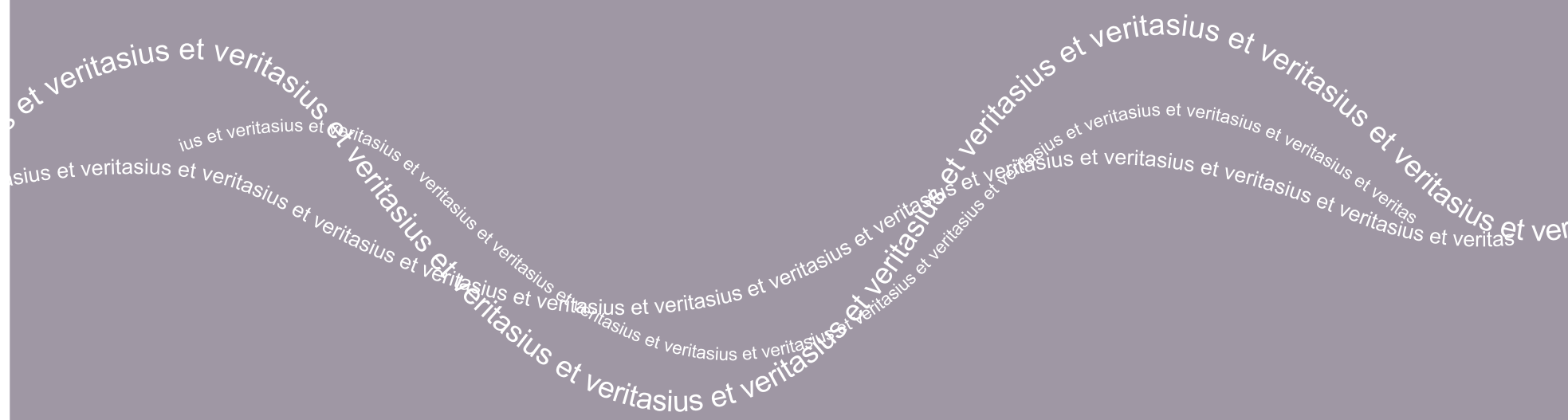


MOISÉS MONTIEL MOGOLLÓN

CATALINA FERNÁNDEZ CARTER JUAN CARLOS OSPINA MICHELLE REYES MILK ANDREA SANTACRUZ SALAZAR SANTIAGO AlBERTO VARGAS NiÑO JORGE RODRÍGUEZ RODRÍGUEZ ALESSANDRA ENRICO HEADRINGTON CARMELA SOFÍA GARCÍA GANOZA DANTE MARTIN PAIVA GOYBURU MELISSA MACHER REYES RUDINEI JOSE ORTIGARA RAQUEL LIMAY CHAVEZ Cyndel CABAllero FERnÁNDEZ Diego Morales Alferrano PERCY ENRIQUE BARDALES CASTRO ANTONIA JABALERA RODRÍGUEZ LUIS DURÁN ROJO ERNESTO PACHAS LUNA

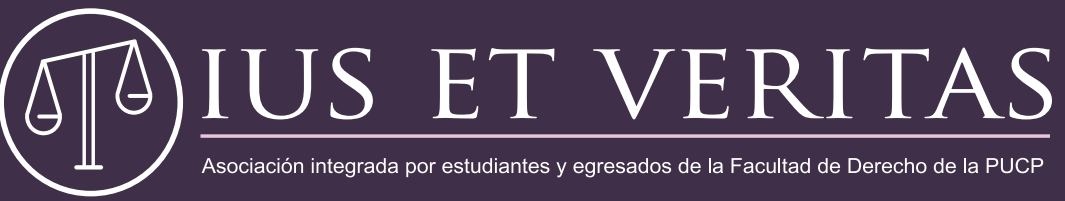
www . i usetveritas . com 